\title{
RECENT ADVANCES IN NUCLEAR POWERED ELECTRIC PROPULSION FOR SPACE EXPLORATION
}

\author{
R. Joseph Cassady, ${ }^{1}$ Robert H. Frisbee, ${ }^{2}$ James H. Gilland ${ }^{3}$ Michael G. Houts, ${ }^{4}$ Michael \\ R. LaPointe, ${ }^{4}$ Colleen M. Maresse-Reading, ${ }^{2}$ Steven R. Oleson, ${ }^{5}$ James E. Polk, ${ }^{2}$ Derrek \\ Russell, $^{6}$ and Anita Sengupta ${ }^{2}$
}

Corresponding author: Michael LaPointe, NASA Marshall Space Flight Center, Huntsville, AL 35812, michael.r.lapointe@nasa.gov, Phone 256-961-7555

\begin{abstract}
Nuclear and radioisotope powered electric thrusters are being developed as primary inspace propulsion systems for potential future robotic and piloted space missions. Possible applications for high power nuclear electric propulsion include orbit raising and maneuvering of large space platforms, lunar and Mars cargo transport, asteroid rendezvous and sample return, and robotic and piloted planetary missions, while lower power radioisotope electric propulsion could significantly enhance or enable some future robotic deep space science missions. This paper provides an overview of recent U.S. high power electric thruster research programs, describing the operating principles, challenges, and status of each technology. Mission analysis is presented that compares the benefits and performance of each thruster type for high priority NASA missions. The status of space nuclear power systems for high power electric propulsion is presented. The paper concludes with a discussion of power and thruster development strategies for future radioisotope electric propulsion systems.
\end{abstract}

\footnotetext{
${ }^{1}$ Aerojet Corp., Redmond, CA

${ }^{2}$ Jet Propulsion Laboratory, Pasadena; CA

${ }^{3}$ Ohio Aerospace Institute, Cleveland, $\mathrm{OH}$

${ }^{4}$ NASA Marshall Space Flight Center, Huntsville, AL

${ }^{5}$ NASA Glenn Research Center, Cleveland, OH

${ }^{6}$ Northrop Grumman Space Technology, Redondo Beach, CA
} 
Keywords: Space propulsion, electric propulsion, electrostatic, electromagnetic, plasma, nuclear

\section{NOMENCLATURE}
$\mathrm{ALFA}^{2}=$ Advanced Lithium-Fed Applied-field Lorentz Force Accelerator
ATLO $=$ Assembly, Test and Launch Operations
$\overrightarrow{\mathrm{B}} \quad=\quad$ Magnetic Field (Tesla)
$\mathrm{Bi}=$ Bismuth (propellant)
$\overrightarrow{\mathrm{E}} \quad=$ Electric field $(\mathrm{V} / \mathrm{m})$
ETRU = Extraterrestrial Resource Units
$\mathrm{eV}=$ electron-Volt
$\mathrm{g}_{0}=$ Gravitational acceleration at sea level, $9.81 \mathrm{~m} / \mathrm{s}^{2}$
FSP $=$ Fission Surface Power
GPHS $=$ General Purpose Heat Source
$\mathrm{H}_{2} \mathrm{O}=$ Water (propellant)
IMLEO $=$ Initial Mass in Low Earth Orbit
INSRP $=$ Intra-agency Nuclear Safety Review Panel
$\mathrm{I}_{\mathrm{sp}} \quad=\quad$ Specific Impulse (s)
$\vec{j}=$ Current density $\left(\mathrm{A} / \mathrm{m}^{2}\right)$
$\mathrm{J}=\operatorname{Current}(\mathrm{A})$
$\mathrm{JMO}^{=}$Jupiter Icy Moon Orbiter
$\mathrm{Li}=$ Lithium (propellant)
$\mathrm{M}_{\mathrm{f}} \quad=\quad$ Final spacecraft mass $(\mathrm{kg})$
$\mathrm{M}_{\mathrm{i}} \quad=\quad$ Initial spacecraft mass $(\mathrm{kg})$ 


$$
\begin{aligned}
& \text { MMRTG }=\text { Multi-Mission Radioisotope Thermal Generator } \\
& \text { MPDT }=\text { Magnetoplasmadynamic Thruster } \\
& \dot{\mathrm{m}}=\text { Propellant mass flow rate }(\mathrm{kg} / \mathrm{s}) \\
& \mathrm{NH}_{3}=\text { Ammonia (propellant) } \\
& \text { NSTAR }=\text { NASA Solar Electric Power Technology Application Readiness } \\
& \text { NuPIT }=\text { Nuclear electric Pulsed Inductive Thruster } \\
& \text { PIT }=\text { Pulsed Inductive Thruster } \\
& \text { PPU }=\text { Power Processing Unit } \\
& \mathrm{q}=\text { Particle charge }(\text { Coulomb }) \\
& \text { RTG = Radioisotope Thermal generator } \\
& \text { SRG }=\text { Stirling Radioisotope Generator } \\
& \mathrm{T}=\text { Thrust }(\mathrm{N}) \\
& \mathrm{u}_{\mathrm{e}} \quad=\quad \text { Exhaust velocity }(\mathrm{m} / \mathrm{s}) \\
& \text { UHV }=\text { Ultra High Voltage } \\
& \mathrm{V}=\text { Applied voltage }(\mathrm{V}) \\
& \text { VHITAL }=\text { Variable Specific Impulse Thruster with Anode Layer } \\
& \mathrm{Xe}=\mathrm{Xenon} \text { (propellant) } \\
& \alpha=\text { Specific mass }\left(\mathrm{kg} / \mathrm{kW}_{\mathrm{e}}\right) \\
& \Phi=\text { Electric potential (V) } \\
& \Delta \mathrm{V}=\text { Mission velocity increment }(\mathrm{m} / \mathrm{s})
\end{aligned}
$$




\section{INTRODUCTION}

Chemical propulsion is at present the only viable technique for lifting payloads from Earth into orbit. Once in space, however, electrically powered thrusters using ionized gas propellants can provide significant advantages over chemical engines for several types of missions. The propellant exhaust velocity produced by chemical combustion is typically well below the optimum exhaust velocity for most missions of interest. By decoupling the energy source from the propellant, electric propulsion (EP) systems can provide substantially higher propellant velocities than chemical engines, albeit at lower thrust. Compared with chemical engines, the higher exhaust velocities offered by electric propulsion can dramatically reduce the amount of propellant required to perform a given mission. The savings in propellant mass can be used to lower mission costs by reducing the vehicle class needed to launch a given payload, or by increasing the amount of payload mass delivered to orbit by a given launch vehicle.

A variety of electric propulsion technologies have been in commercial use for several years, and over 160 satellites now flying in earth orbit employ some form of electric propulsion. Current electric propulsion systems operate at average power levels of several watts to a few kilowatts, but research into higher power electric thrusters is underway to support more demanding potential space science and exploration missions. These potential future missions include orbit raising and station keeping for large platforms, the transport of cargo to sustain the human exploration and colonization of the moon and Mars, asteroid rendezvous and automated sample return missions, robotic deep space exploration, and at very high power, fast piloted missions to Mars and the outer planets. The following section provides an introduction to electric propulsion, outlining the major 
types of thrusters and their principles of operation. A brief overview is then provided of the key components that make up a nuclear electric propulsion system. Following this background, the status of several recent U.S. high power electric thruster research and development programs is discussed, and thruster options are compared for various high priority NASA missions. The status of nuclear fission development programs relevant to nuclear electric propulsion is briefly described, and the review concludes with a detailed discussion of low power radioisotope electric propulsion systems considered for robotic deep space exploration.

\section{ELECTRIC PROPULSION FUNDAMENTALS ${ }^{1}$}

Unlike conventional chemical rockets, in which chemicals react to heat a propellant, electric propulsion systems use electricity in the form of applied electric fields, currents, and/or magnetic fields to accelerate a propellant for thrust. Options for electric propulsion thrust generation include simple electrical heating and expansion of neutral gas propellants (electrothermal acceleration); acceleration of charged ions using static electric fields (electrostatic acceleration); and acceleration of current-carrying quasi-neutral plasma using electromagnetic Lorentz forces (electromagnetic acceleration). As discussed below and in later sections, some electric propulsion systems employ more than one of these acceleration mechanisms. Different systems may require continuous or pulsed electrical power, and each EP technology provides unique benefits and challenges. The inherent physics of each thruster type determines its performance regime, which must be matched to mission requirements. However, by decoupling the power source from the propellant, all electric propulsion systems are capable of accelerating propellant to significantly higher exhaust speeds $\left(\mathrm{u}_{\mathrm{e}}\right)$ than chemical engines. As noted earlier, this corresponds to a significant reduction in the required propellant mass, as shown by the rocket equation:

\footnotetext{
${ }^{1}$ James Gilland, Ohio Aerospace Institute (james.h.gilland@grc.nasa.gov)
} 


$$
\frac{M_{f}}{M_{i}}=e^{-\frac{\Delta V}{u_{c}}}
$$

where $M_{f}$ is the final spacecraft mass at the destination, $M_{i}$ is the initial spacecraft mass (including propellant), and $\Delta \mathrm{V}$ is the change in spacecraft velocity required to perform the mission. By increasing the propellant exhaust velocity relative to the mission $\Delta \mathrm{V}$, a higher fraction of the initial spacecraft mass can be delivered to the destination. It is this feature that makes electric propulsion particularly advantageous for difficult, high $\Delta \mathrm{V}$ missions, such as robotic science missions to the outer planets and large cargo missions in support of human space exploration.

Electric propulsion system performance, in particular engine thrust, is limited by the amount of power that can be imparted to the propellant. EP systems require an electric power supply, which is carried on-board the spacecraft throughout the mission. The mass of the power supply reduces the spacecraft mass budget that can be allocated to the payload. Unlike chemical rockets, an EP thruster must accelerate not only the payload and propellant, but also the thruster power system. As discussed below, the mass of the power system, and the inherent scaling of thrust to power in electric propulsion systems, results in typically low spacecraft accelerations on the order of $10^{-3} \mathrm{~m} / \mathrm{s}^{2} \cdot[1]$ Electric thrusters must generally operate for an extended period of time to provide the required spacecraft velocities.

\subsection{EP Figures of Merit}

To determine the performance of an EP thruster for a given mission, multiple aspects of the propulsion system must be considered. A successful mission is defined by both payload delivery and by mission time, and reducing the propellant mass by increasing the 
exhaust velocity is just the first step in determining the effectiveness of the propulsion system. The performance of an electric propulsion system, which includes the on-board power system, can be defined by a set of four parameters: specific impulse $\left(\mathrm{I}_{\mathrm{sp}}\right)$, thrust efficiency $(\eta)$, specific mass $(\alpha)$, and lifetime.

Specific impulse $\left(\mathrm{I}_{\mathrm{sp}}\right)$ is defined as the thrust per unit weight of propellant flow, measured at sea level:

$$
\mathrm{I}_{\mathrm{sp}}=\frac{\mathrm{T}}{\dot{\mathrm{m}} \mathrm{g}_{0}}=\frac{\mathrm{u}_{\mathrm{e}}}{\mathrm{g}_{0}}
$$

where $\dot{\mathrm{m}}$ is the propellant mass flow rate, $\mathrm{T}$ is the engine thrust $\left(\dot{\mathrm{mu}}_{\mathrm{e}}\right)$, and $\mathrm{g}_{0}$ is the acceleration due to gravity at sea level. Following common usage, the exhaust velocity is typically expressed as a specific impulse value. Trades to reduce propellant mass and increase power system mass for a fixed mission mass and trip time typically lead to a range of optimum $\mathrm{I}_{\mathrm{sp}}$ values which maximize the delivered payload.[2]

Thrust efficiency $(\eta)$ is the ratio of kinetic power useful for thrust to the electrical power input to the thruster:

$\eta=\frac{\frac{1}{2} \mathrm{u}_{\mathrm{e}} \mathrm{T}}{\mathrm{JV}}=\frac{\frac{1}{2} \mathrm{I}_{\mathrm{sp}} \mathrm{g}_{0} \mathrm{~T}}{\mathrm{JV}}$

where the electrical power is the product of total current $(I)$ and voltage $(V)$ input to the thruster. For a given $\mathrm{I}_{\mathrm{sp}}$ and input power, higher efficiency indicates greater thrust and increased vehicle acceleration, which in turn reduces mission trip times.

Specific mass $(\alpha)$ is the ratio of the power and propulsion system mass to the electrical power generated. This is usually stated in units of $\mathrm{kg} / \mathrm{kWe}$. Lower specific mass provides a lighter vehicle and greater acceleration.

Lifetime is the length of time the EP thruster can operate before failure. EP thrusters typically have material surfaces in direct contact with hot plasma, and damage can result from heating, 
sputtering, or electric arcing. Because of the low acceleration provided by EP systems, lifetimes on the order of months or years are typically required. If operational lifetimes are too short then replacement thrusters would be required during the course of the mission, which increases system mass and complexity.

\subsection{Categories of Electric Propulsion}

As noted, electric propulsion relies on the conversion of electric power into directed thrust. This can be accomplished in a variety of ways, ranging from simple electrothermal heating of the propellant gas to more complex electrostatic and electromagnetic acceleration of ionized gas propellants.

\section{Electrothermal Thrusters}

Electrothermal propulsion systems are typically low power, direct current devices that heat propellant gas either indirectly using a resistively heated solid element (resistojet), or directly by passing current through a gas (arcjet). Both thruster technologies are mature and have successfully flown on spacecraft for several decades.[3] Electrothermal heat addition limits these devices to specific impulse values less than $2000 \mathrm{~s}$, which are useful for near-Earth orbit applications but are generally inadequate for space exploration missions beyond low Earth orbit. As such, these devices are not generally considered for nuclear electric power mission applications, and will not be considered further in this review.

\section{Electrostatic Thrusters}

Electrostatic propulsion systems, which apply a static electric potential to accelerate charged ions, are one of the oldest and most effective means of particle acceleration. Ions 
are accelerated to an exhaust speed $u_{e}$ determined by the particle mass $\left(m_{i}\right)$, charge $(q)$, and applied potential $(\Phi)$ :

$$
u_{e}=\sqrt{\frac{2 q \Phi}{m_{i}}}
$$

The two fundamental types of electrostatic accelerators developed for spacecraft propulsion are the gridded ion thruster and the Hall-effect thruster. As discussed below, each type differs in the means used to generate the accelerating potential, leading to different performance regimes and technical challenges. Extensive flight experience has been gained with both types of electrostatic thrusters, and they are widely used for satellite station-keeping and orbit maneuvering.

Gridded Ion Thruster The initial concept for an ion thruster appears in the writings of both Goddard and Tsiolkovski.[4] As shown in Fig 1a, the thruster consists of three essential components: a discharge chamber, a set of accelerating grids, and a neutralizer. Electrons generated by the hollow cathode are attracted to the positively charged walls of the discharge chamber and collide with the propellant gas to create plasma; alternative discharge chamber designs may use inductive [5] or microwave electron cyclotron resonance ionization techniques to create the plasma.[6,7] The resulting discharge chamber plasma is magnetically confined by arrays of permanent magnets in a "ringcusp" configuration, which serves to extend the residence time of the bombarding electrons within the chamber.[8] A potential difference on the order of kilovolts is applied across a set of closely spaced perforated grids located at the downstream end of the discharge chamber. The large electric field established between the grids accelerates the ions out of the discharge chamber at high velocity. An external neutralizer cathode, 
typically a second hollow cathode mounted outside of the discharge chamber, generates electrons to neutralize the positively charged ion exhaust and prevent it from returning to the spacecraft.

Gridded ion thrusters trade complexity of construction for simplicity of operation. Multiple power supplies are required to operate the discharge chamber, accelerating grids, and neutralizer. In return, the efficiency and exhaust velocities of these devices can be quite high, as discussed in later sections of this paper. The maximum operating current density for a gridded ion thruster is limited by Child-Langmuir space charge constraints and by material erosion. High velocity charge-exchange ions from the exhaust plume can return to impact the grid structure and sputter material from the surfaces, leading to progressive grid erosion and eventual thruster failure.[9] Such issues lead to the use of relatively large grid areas for high power thruster operation, which in turn increases the thruster specific mass.[10] Additional information on high power gridded ion thrusters and their current development status is presented in Section 3.1.

Hall-Effect Thruster As their name implies, Hall-effect thrusters take advantage of the mean Hall drift of charged particles in a direction perpendicular to a set of orthogonal electric and magnetic fields: A basic Hall thruster schematic is shown in Fig 1b. A radial magnetic field is created within a discharge channel using concentric magnetic pole pieces energized by electromagnetic windings. The back of the discharge channel is biased to positive anode potential, and attracts electrons generated by an external hollow cathode. The axial electric field and radial magnetic field cause the electrons to drift azimuthally in the strong magnetic field region, effectively increasing the impedance of the anode-cathode gap to produce a large electrostatic potential. Propellant ions, created 
by electron impact ionization, remain largely un-magnetized and are electrostatically accelerated out of the discharge chamber to provide thrust. Unlike gridded ion thrusters, Child-Langmuir limits do not occur in Hall thrusters, which instead depend on tailored magnetic field profiles to efficiently ionize and accelerate the propellant ions. As such, Hall thrusters can operate at higher plasma densities and provide a correspondingly higher thrust density than gridded ion thrusters. Hall thruster variations, such as the Thruster with Anode Layer (TAL) and Stationary Plasma Thruster (SPT), primarily differ in the material composition and length of their discharge channels, which provide different ionization and acceleration regimes.[11] Hall thruster lifetimes up to 7400 hours have been demonstrated in low power devices, and lifetimes approaching 8000 hours are anticipated in high power thrusters[12]. Hall thruster lifetimes are primarily limited by plasma erosion of the ceramic discharge channel walls. Additional information on high power Hall thruster technology is provided in Section 3.2.

\section{Electromagnetic Thrusters}

Electromagnetic propulsion systems use the Lorentz force that arises from the orthogonal application of orthogonal currents $(\vec{j})$ and magnetic fields $(\vec{B})$ :

$$
\mathrm{T}=\int \overrightarrow{\mathrm{j}} \times \overrightarrow{\mathrm{B}} \mathrm{dV}
$$

where the integral is taken over the volume occupied by the current-carrying plasma in the thruster.[2] There are two primary cylindrical topologies used to generate an axial Lorentz force in electromagnetic thrusters: radial currents acting with azimuthal magnetic fields $\left(\mathrm{j}_{\mathrm{r}} \mathrm{B}_{\theta}\right)$, or azimuthal currents acting with radial magnetic fields $\left(\mathrm{j}_{\theta} \mathrm{B}_{\mathrm{r}}\right)$. These 
mechanisms are embodied by the magnetoplasmadynamic (MPD) thruster and the pulsed inductive thruster (PIT), respectively.

Magnetoplasmadynamic (MPD) Thruster In an MPD thruster, gas propellant is typically injected through the thruster backplate. Currents driven between an outer cylindrical anode and concentric inner cathode by an applied voltage ionize the propellant and produce a radial current flow between the electrodes. The return current flowing through the cathode produces an azimuthal magnetic field, which interacts with the radial current to axially accelerate the plasma, and with the axial current to compress the plasma toward the centerline (Fig 2a). In this self-field thruster configuration, thrust scales with current and thruster geometry as $\mathrm{T}=\mathrm{bJ}^{2}$, where $b$ is a geometric parameter and $J$ is the total current through the thruster. In applied-field MPD thrusters, external magnet coils are used to apply axial and radial magnetic fields to help stabilize the discharge, or to provide additional accelerating Lorentz forces through interactions with applied radial currents and azimuthally induced currents within the thruster.[13]

High thrust and a corresponding improvement in MPD thruster efficiency occurs with high current operation, corresponding to high input power. Laboratory MPD thrusters typically operate between $100-\mathrm{kW}$ and $10-\mathrm{MW}$, the latter in pulsed mode to alleviate ground test facility requirements.[14] The intermittent development and experimental status of these high power devices limits the available performance data, and a fully optimized MPD thruster has not yet been developed. Results to date demonstrate that the primary MPD thruster wear mechanism is the erosion of the central cathode through sputtering and local arc attachments.[15] High power thruster lifetimes of $5000 \mathrm{~h}$ to $10000 \mathrm{~h}$ are desirable for most mission applications, but have not yet been demonstrated 
due to ground facility limitations. Recent advancements in the development of high power MPD thruster technology are presented in Section 3.3.

Pulsed Inductive Thruster (PIT) The PIT (Fig 2b) delivers a high power current pulse through a flat, multi-turn coil to generate a strong radial magnetic field, which in turn induces an azimuthal electric field in the region above the coil. The induced electric field ionizes a thin layer of injected gas propellant and generates an azimuthal current within the newly formed plasma; the radial magnetic field interacts with this induced azimuthal current to provide the accelerating axial Lorentz force. Propellant gas injected through a fast-acting valve atop a pylon in front of the coil provides a nearly uniform mass layer over the coil surface prior to the current pulse. A significant benefit of the PIT is its electrodeless operation, which allows the use of various propellants such as oxygen and other in-situ gases. Because these high temperature and potentially corrosive plasmas do not come into direct contact with material surfaces, erosion issues are not a serious concern. However, the PIT is inherently pulsed and may require up to $10^{10}$ discharges for missions of interest[16], necessitating significant advancements in repetitively pulsed high power switch and circuit technologies. The operation and status of the Pulsed Inductive Thruster is further described in Section 3.4.

\section{Advanced Thruster Concepts}

Advanced plasma propulsion systems which do not fall under the general electric propulsion categories outlined above are also being investigated. Of current interest is the use of plasma waves to heat magnetized plasma, which is then expelled through a diverging magnetic field (magnetic nozzle). In general, propellant is injected into a dielectric walled chamber; a radiofrequency antenna surrounds the chamber, and an 
external magnetic field coil generates the magnetic field necessary for plasma wave propagation. Radio waves directed at the plasma by the antenna are absorbed by ions or electrons, depending on the chosen frequency. For resonance heating, the applied electromagnetic fields are tuned to the natural cyclotron frequencies of the ions or electrons. In collisional heating, the electromagnetic fields cause the particles to oscillate, and energy is delivered through collisions with other particles. In either case, the wave energy is converted into plasma thermal energy, and the thermal energy is converted into kinetic energy in the expanding magnetic field. These concepts are at a very low level of development, and their performance has not yet been measured. Issues remain concerning the efficiency of plasma production and expansion, as well as the system level design and integration of such concepts onto spacecraft. However, such electrodeless concepts do offer the potential for long life, high specific impulse operation. Two representative concepts are shown in Fig 3; the ECR thruster, which uses electron cyclotron resonance heating [17], and the VASIMR thruster, which uses ion cyclotron resonance (ICR) heating.[18] Due to their lower level of technical maturity, these concepts are not described further in this review article.

\section{NUCLEAR ELECTRIC PROPULSION SYSTEMS ${ }^{1}$}

The total vehicle and mission performance of a nuclear electric propulsion system strongly depend on the characteristics of the nuclear power system.[19] In particular, the specific mass, $\alpha$, of the power system tends to dominate that of the electric propulsion system. As described in Section 2.1, the total system $\alpha$ determines the overall vehicle acceleration and therefore the trip time and payload fraction capabilities. Minimization of

\footnotetext{
${ }^{1}$ James Gilland, Ohio Aerospace Institute (james.h.gilland@grc,nasa.gov)
} 
system $\alpha$ requires an optimization of the total NEP power and propulsion system, the principal components of which are outlined below.

\subsection{NEP Component Technologies}

The fundamental requirement of a nuclear electric propulsion system is to convert the thermal energy of the reactor into directed kinetic energy of the propellant. To accomplish this task in space requires systems to handle the useful converted energy as well as the waste energy. The components to convert heat to electricity, and reject the waste power, are described below.

A typical nuclear electric propulsion system is shown schematically in Fig 4. The essential NEP components are the reactor, power conversion system, heat rejection system, and power management and distribution (PMAD) system. These primary components and their key performance parameters, as well as the interplay between components in NEP system designs, are discussed below.

\section{$\underline{\text { Reactor }}$}

As the heat source for the power generation system, the reactor must generate power at a high temperature for a long period of time. High temperature is desirable to maximize the thermodynamic efficiency of the total system. Because heat rejection in space is to a fixed background temperature, the Carnot efficiency of the power system is determined by the source temperature. Since heat rejection is by radiation alone, the performance of the heat rejection system is also very sensitive to the peak operating temperature of the cycle. Space reactor design temperatures ranging from 900 to $1500 \mathrm{~K}$ have been considered:[20] 
The requirement for long duration operation stems from the nature of low thrust electric propulsion missions, which typically operate continuously over the entire life of the mission. Most NEP missions of interest have durations of 1 to 10 years, with the possible reuse of the vehicle driving the required lifetime to the multiyear regime. The reactor lifetime requirement also drives another reactor design characteristic, the fuel burn-up fraction. This is the percentage of the fissile fuel that can be used without affecting reactor performance or safety due to the creation of radioactive byproducts. The technology challenge in these conflicting requirements is to provide long life at high temperatures. This is further discussed in Section 6.0.

\section{Power Conversion}

The principal power conversion systems proposed for space nuclear power include both static systems, such as thermoelectric or thermionic converters, and dynamic systems such as Brayton, Rankine, and Stirling engines.[21] As with the reactor system, these high performance components require operation at high temperature over perhaps tens of thousands of hours. Power conversion efficiency is a factor of both the inlet and outlet temperatures, and significant materials issues, such as strength and dimensional stability, arise from these requirements.

\section{Heat Rejection}

The waste energy from the reactor, power conversion system, electric thruster, and vehicle electronics must be rejected to space through radiation. The size and mass of the space radiator system are dependent on two key factors: the amount of waste heat to be rejected, and the temperature of the radiator. The power conversion efficiency increases 
with lower rejection temperatures, which reduces the amount of heat to be radiated away. But the radiator area increases with lower rejection temperature, resulting in a larger mass for the radiator system. These factors lead to an inverse and competing relationship between efficiency and radiation temperature, which in turn impacts the size and mass of the radiator system. Because the heat rejection system mass is a significant and often dominant portion of the overall NEP system mass, design trades are required to minimize the total mass based on the relative masses of the reactor and radiator systems.

\section{Power Management and Distribution}

Power switching and transmission from reactor to thruster become particular challenging for high $(>10 \mathrm{kWe})$ power electric propulsion systems. Desirable characteristics for PMAD systems include system reliability over multiple cycles, safely switching high voltage or high current for use by the electric propulsion system, efficient power processing and transmission to reduce waste heat, and low system mass to reduce total system $\alpha$. A particular concern in PMAD designs is the maximum allowable operating temperature for the power electronics. State-of-the-art electronics operate at lower peak temperatures than the rest of the power conversion system, necessitating a larger radiator area to reject waste heat. To integrate the power system to the electric thruster, additional issues of AC versus DC generation and transmission, and high voltage versus high current transmission, must be considered when designing the overall PMAD system.[22] 


\section{RECENT ADVANCES IN HIGH POWER ELECTRIC PROPULSION}

In 2003, NASA established the Prometheus Power and Propulsion Office to advance the state of the art in nuclear power and propulsion to meet future NASA mission requirements. Key to these efforts was the development of high power electric thruster technologies that, combined with space nuclear power sources, could provide the foundation for these bold new exploration missions.[23] Mission attributes enabled by high power NEP technologies include greater launch window flexibility, enhanced spacecraft maneuverability at the destination planetary system, more sophisticated active and passive remote sensing capabilities, and greatly increased science data return rates. The following sections provide an overview and status of these recent high power NEP development activities.

\subsection{Ion Thruster Technology Development for the Jupiter Icy Moons Orbiter Project $^{1}$}

The first mission proposed under the Prometheus project was the Jupiter Icy Moons Orbiter (JMO), which focused on the potential development and use of a 100-kW class spacecraft propelled by electric thrusters. The proposed JIMO mission had two principle objectives: to tour and characterize three icy moons of Jupiter (Callisto, Ganymede, and Europa), and to demonstrate nuclear electric propulsion (NEP) flight system technologies for future planetary and solar system exploration missions.[24] The final requirements for JMO were still under review by independent government and industry teams when JMO was cancelled in 2005. Prior to cancellation, however, the top-level electric propulsion system characteristics were identified. The requirements included power levels of $20-\mathrm{kW}$

\footnotetext{
${ }^{1}$ Steven Oleson, NASA Glenn Research Center (steven.r.oleson@nasa.gov)
} 
to $50-\mathrm{kW}$ per thruster; specific impulse values of 2000 to $9000 \mathrm{~s}$; system operation for 6 to 10 years; radiation tolerance to the Jupiter environment; and demonstration of technology maturity prior to Preliminary Design Review (PDR). The latter requirement necessitated that all development models (breadboard hardware, computer models, etc.) must have been demonstrated, all major technology risks and manufacturing issues resolved, and detailed plans to accumulate system life data were to be written and approved prior to PDR. Given these constraints, gridded ion thrusters were selected for the JMO mission baseline design due to their maturity, efficiency, demonstrated operational lifetime, and ability to provide the high specific impulses required by such high energy missions.

\section{JIMO Technology Challenges for Ion Propulsion}

While the ion propulsion system appeared to be the best option for the JMO spacecraft, the daunting mission requirements introduced several major new development challenges. Table 1 compares the propulsion technology needs for JIMO with present ion thruster technology, as represented by the NASA Solar Electric Power Technology Application Readiness (NSTAR) thruster recently flown on the NASA Deep-Space 1 spacecraft.[25] The table identifies the technology challenges with respect to each electric propulsion subsystem, and highlights the technology areas that required improvement for the JMO mission. Proposed technology solutions that address each of these challenges are also listed in the table.

\section{JMO Ion Thruster Development}

In 2002 NASA published a Research Opportunities in Space Science (ROSS) solicitation, which contained the topic "High Power Electric Propulsion for Near-Term 
Nuclear Systems". Two proposals for ion thruster development were awarded: the High Power Electric Propulsion (HIPEP) ion thruster, and the Nuclear Electric Xenon Ion System (NEXIS) ion thruster. Initially awarded through the In-Space Propulsion Office, these high power electric propulsion development projects were transferred to the Prometheus Project office, and subsequently to the JIMO project. The HIPEP and NEXIS projects are discussed below, together with other key development activities undertaken as part of the JIMO project.

High Power Electric Propulsion System (HIPEP) The goal of the HIPEP effort, led by the NASA Glenn Research Center, was to develop and demonstrate a $25-\mathrm{kWe}$ ion thruster operating at a specific impulse of approximately 8000 s. The HIPEP thruster was designed to include either microwave or hollow-cathode discharge sources and neutralizers, and a rectangular discharge chamber and grid geometry that could potentially scale more easily scaled with power than cylindrical engine designs.[26]

The JMO-HIPEP team explored various plasma production options, including DC hollow cathode and $\mathrm{AC}$ microwave discharges.[27] Both approaches were used during the HIPEP project, demonstrating that either option can be used with the rectangular chamber design. Using the microwave source, the HIPEP thruster was operated up to 16 $\mathrm{kW}$, with power limited by the available microwave supply. Operated with hollowcathode sources (Fig 5a), the thruster ran at discharge powers up to $40 \mathrm{~kW}$. Thruster efficiencies exceeded $72 \%$ for specific impulse values between $6000 \mathrm{~s}$ and $10,000 \mathrm{~s}$, and reached over $75 \%$ at peak power. The rectangular HIPEP thruster shape enhances the packaging of multiple thrusters on a single spacecraft; multiple thrusters installed next to one another will minimize structural elements, and provide a dense cluster of aligned 
beams. The rectangular shape also allows the thrust chamber and grids to be easily scaled without extensive redesign. Early thruster designs used curve titanium grids to demonstrate electrostatic performance; later tests successfully incorporated flat pyrolitic graphite grids to increase thruster lifetime. Operated with pyrolitic grids, the HIPEP thruster is projected to achieve $100 \mathrm{~kg} / \mathrm{kW}$ of xenon propellant throughput, at both $8000 \mathrm{~s}$ and $6000 \mathrm{~s}$ specific impulse.[28-32] Analytic results also project that these flat grids, with a properly designed HIPEP flight thruster, can survive the rigors of launch with adequate margin:[33]

Based on the success of the HIPEP lab model testing, work began on two development models to address various form, fit, and function challenges based on the ROSS solicitation requirements. The first model was used in a $2000 \mathrm{hr}$ wear test, which was successfully completed in 2005. [34-36]. Although short compared to the required 6-10 year thruster lifetimes expected for JMO, this initial test began to assess the long life features of the thruster and demonstrated the ability of the design to operate over a long period. A second HIPEP thruster model was also constructed, and saw limited use in performance and integration testing prior to JMO project termination.[37]

Nuclear Electric Xenon Ion System (NEXIS) Thruster The NEXIS thruster effort, led by the NASA Jet Propulsion Laboratory, focused on the development of a $20-\mathrm{kWe}$ ion engine to operate at $7500 \mathrm{~s}$ specific impulse. State of the art performance and life assessment tools were used in the thruster design. The primary goal of the effort was to improve thruster life by improving the discharge cathode and neutralizer, and by developing and using carbon composite grids.[38] Additional details of the NEXIS project are described in [38-40] and references therein. 
The NEXIS team demonstrated a $65-\mathrm{cm}$ laboratory model ion thruster (Fig 5b), as well as a long life reservoir cathode that operated successfully over a 2000 -hr wear test.[41] The NEXIS thruster was operated at power levels up to $27 \mathrm{~kW}$, and achieved up to $81 \%$ efficiency for specific impulse values between 6500 s and 8700 s. The large circular thruster incorporated a multi-magnet ring design, and successfully operated with both flat and dished carbon-carbon (C-C) grids. Analysis of the dished C-C grids indicates they will survive launch loads. The NEXIS thruster, operated with C-C grids, is projected to provide the $100-\mathrm{kg} / \mathrm{kW}$ xenon throughput margin specified for the JIMO mission.[38]

Based on the success of the laboratory model thruster tests, development models were built to address various form, fit, and function challenges. The first development model completed performance testing and was used in a $2000 \mathrm{hr}$ wear test.[39] Although again short compared to the required 6-10 year lifetime expected for JIMO, this test began to assess the long life features of the NEXIS thruster and demonstrated the ability of the thruster to operate for long periods of time. A second NEXIS design model successfully completed a vibration test at full Prometheus-1 proto-flight levels, prior to JIMO project termination.

\section{High Voltage Propellant Isolators and Insulators}

Electrical isolation between the propellant tanks held at spacecraft potential and the charged ion thruster discharge chamber has always raised concerns of reliability and durability. In addition, the need to sustain high voltage differences between adjoining thruster components while mechanically supporting the thruster body and ion optics requires a trade between size, weight, structural considerations, and material durability. 
Ultra high voltage (UHV) propellant isolators and electrical insulators will be necessary for the higher power, high specific impulse ion thrusters envisioned for Prometheus missions. Electrical isolation up to $6500-\mathrm{V}$ will be required, necessitating $15000-\mathrm{V}$ stand offs to assure adequate safety margins. To address this issue, an array of UHV xenon propellant isolators and insulators were constructed and evaluated during the JIMO project to quantitatively measure limits and safety margins.[42] Shadow shield designs, tolerance to contamination, and Paschen voltage breakdown were evaluated for UHV propellant isolators and insulators. Test results were compared with stretched segmented isolators and large-gap insulators similar to those used on the NSTAR thruster. A down selection was made to two insulator concepts: a grooved external surface ceramic-tometal sealed alumina " $\mathrm{H}$ " cross-section cylinder, and a smooth external surface ceramicto-metal sealed alumina " $\mathrm{H}$ " cross-section cylinder. Final UHV insulator selection will be based on a combination of factors including performance, reliability, durability, size, range of operating pressure, and cost.

\section{Ion Engine Life Modeling \& Testing}

Future NEP missions will require the electric propulsion subsystems to operate for several years, significantly longer than the operational times demonstrated to date. Due to current ground facility cost and scheduling constraints, thruster lifetimes must be validated using a combination of analysis, numerical models, experimental data, and accelerated life tests.[43-49] Significant progress has been made in developing and refining predictive life models based on existing experimental data, with limited ground tests used to validate the model results. Prior ion thruster ground tests, including the 30,000 hour NSTAR extended duration ground test [50], have identified most of the 
major life limiting processes that occur in ion thrusters. Although the concept of life test by analysis is still being developed, it is clear that code validation will need to be maintained through a formal design basis document, with configuration control that includes technical justification of all design parameters entering the analysis. Model refinement and validation using accelerated wear tests would be used to provide continual improvements in thruster subcomponent and system level codes.

\section{Radiation Hardened Materials and Components}

Among the unique challenges posed by the JMO project is the high radiation environment surrounding Jupiter. Ionizing radiation doses as high as 5-Mrad near Europa necessitate the qualification of ion thruster materials and components tolerant to these extreme environments.[51] During the JMO project, specific ion thruster materials and components were identified that are potentially vulnerable to degradation in the near Jupiter environment. Literature searches on material properties were conducted, along with material and component tests using ionizing radiation to evaluate material performance and durability. Electrical and mechanical properties were evaluated for selected thruster components. Functional characteristics, such as electrical breakdown strength and leakage current during operation in a representative radiation environment, were planned but were not performed prior to JMO project termination.

\section{Gridded Ion Power Processing Units}

State-of-the-art power processing units (PPUs) use DC-DC converters or power supplies to transform input power into isolated and regulated thruster power. The PPU also provides telemetry interface with the spacecraft, high voltage recycle control to extinguish thruster arcs, and thruster cross-strapping capability when multiple thrusters 
are operated from a single PPU. State-of-the-art power processing units contain literally thousands of electronic parts, and typically operate at peak efficiencies of around $94 \%$. High power electric propulsion systems pose their own unique PPU design challenges. Scaling a state of the art electric thruster PPU for a high power JMO class mission generates a significant increase in parts count, which together with an associated increase in heat loss could adversely impact spacecraft mass and reliability.

Several power conversion system options were explored for the proposed JMO mission. Using a DC bus voltage requires the development of higher voltage, higher power converter modules than those used for the NSTAR thruster (see Table 1). These same converter modules could be used with an $\mathrm{AC}$ bus voltage by rectifying the voltage, but a more simple approach is to utilize transformers to provide the higher beam voltages. DC power for the thruster is then obtained by rectifying and filtering the $\mathrm{AC}$ inputs. This system could potentially result in a simpler and more efficient high power PPU, with hundreds versus thousands of parts and efficiency values as high as $98 \%$.

As part of the JMO project, the work on power processing units primarily focused on the development of new components for high power $\mathrm{AC}$ and DC PPUs.[52] A sub-scale, proof-of-concept breadboard beam power supply was built and successfully tested. Beam module tests demonstrated sufficiently low noise and low ripple. A DC-powered accelerator grid power supply was also built and successfully tested. Efforts were underway to fabricate additional beam modules to create a complete beam supply when the JIMO project was terminated. 


\section{Propellant Management}

The proposed JIMO mission required a significant propellant load of approximately $8000 \mathrm{~kg}$ of xenon, with propellant storage times exceeding ten years. These requirements necessitated the development of propellant feed system components with high accuracy and long life. Trade studies of xenon feed system designs were performed in order to reduce the flow uncertainty to $\pm 1 \%$ over a 10 -year mission. The NSTAR ion thruster used a conventional bang-bang cyclic regulation system that, while very rugged, was not practical for a JMO mission due to the large number of required operating cycles. Other options do exist that can provide a rugged and highly accurate feed system, but the components are not rated for the intense Jupiter radiation environment. Prior to project termination, a technology development effort was initiated to radiation harden these propellant feed system components. In addition, more efficient propellant management systems were designed process the residual, low pressure xenon gas anticipated to remain in the propellant tank near the end of the mission.

In summary, significant advancements were made in the development of high power ion thrusters and associated component technologies during the abbreviated two year period of the NASA Jupiter Icy Moon Orbiter project. Advanced gridded ion thrusters capable of processing $100-\mathrm{kg} / \mathrm{kW}$ of xenon propellant were designed, fabricated and tested. High voltage power processing units, radiation hardened materials, and numerical models for extended duration life predictions were developed, and directions identified for future high power ion thruster system development. The work performed and documented through the $\mathrm{IMO}$ project provides a solid foundation for the use of high power gridded ion thrusters on potential future NEP missions. 


\subsection{Very High Isp Thruster with Anode Layer (VHITAL) ${ }^{1}$}

Funded through the NASA Prometheus project office, VHITAL is a technology assessment program led by Stanford University, the NASA Jet Propulsion Laboratory, and TsNIIMASH-Export to evaluate a two-stage thruster with anode layer hall-effect technology as a primary propulsion alternative for high power NASA science missions. Key products of the program include a radiatively cooled two-stage VHITAL thruster operated with bismuth propellant, and an assessment of this technology for NASA missions. The VHTAL-160 thruster design is based on the D160 and D200 TALs developed by the Russian institute TsNIIMASH over 25 years ago.[53] At that time, TsNIIMASH demonstrated this technology up to $140 \mathrm{~kW}$ and $8000 \mathrm{~s}$ specific impulse at thrust efficiencies in excess of $70 \%$. In 2006, the VHITAL program successfully resurrected this promising technology by demonstrating the VHTTAL-160 thruster at 25 $\mathrm{kW}$ and $36 \mathrm{~kW}$ and 6000 to $8000 \mathrm{~s}$ specific impulse (Fig 6). The VHITAL-160 utilizes the magnetic channel design and physical geometry of the D160 thruster, and the radiative cooling scheme of the D200 thruster. VHITAL-160 offers an in-space propulsion system with a unique combination of high power, high efficiency, and low cost propellant system attributes that are attractive for a range of missions, from deep space exploration to Mars and lunar cargo missions.

\section{Systems Engineering Advantages}

The two-stage bismuth thruster technology has several advantages for high power operation compared with conventional single-stage Hall thrusters and high power gas-fed

\footnotetext{
${ }^{1}$ Anita Sengupta (anita.sengupta@jpl.nasa.gov), Colleen Maresse-Reading (colleen.m.maressereading@jpl.nasa, gov); NASA Jet Propulsion Laboratory
} 
gridded ion thrusters. These advantages include operation at high specific impulse, high thrust density, low propellant cost, and reduced pumping speed requirements for ground testing. The high thrust density of a two-stage TAL reduces the total number of thrusters needed for a given mission, reducing the propulsion system footprint on the spacecraft. The use of condensable bismuth propellant has several advantages over xenon fed propulsion systems. Bismuth is stored as a solid at room temperature and is five times denser than xenon stored at supercritical pressures, providing significant tankage fraction and feed system mass savings. Bismuth has a higher atomic mass and lower ionization potential than xenon, which increases electrical and thruster efficiency, respectively, for the same propellant utilization. Often overlooked in the development of high power plasma propulsion systems is the need to test the thrusters in a simulated environment (vacuum facility) on the ground. At a melting temperature of $271^{\circ} \mathrm{C}$, the bismuth propellant plume readily condenses on vacuum facility walls, which significantly reduces the pumping speed requirements for testing bismuth fueled thrusters. As such, two-stage TAL propulsion systems can be tested at power levels exceeding 1-MW in existing vacuum chamber facilities, whereas noncondensable gas-fed MW-class thrusters cannot.

\section{VHITAL Two-Stage Technology}

The two-stage design is unique for Hall thrusters because it separates the ionization and acceleration processes. The bismuth is $90 \%$ ionized in the first stage of the thruster with a discharge of only $150-250 \mathrm{~V}$. The bismuth ions are then accelerated through more than $8000 \mathrm{~V}$ in the second stage of the thruster. Separating the regions of the plasma has several advantages. In a single-stage device, the total accelerating voltage is used to both ionize and accelerate the propellant, and energy is lost in creating high energy electrons 
that cannot efficiently ionize the propellant. These high energy electrons also heat the anode, preventing high specific impulse operation due to material thermal constraints. In the two-stage device, a more efficient ionization region is maintained by the relatively low voltage and electric field of the first stage, while the high accelerating voltage and electric field in the second stage can efficiently accelerate the ions. The two-stage design also enables ionization to occur at lower current densities than in a single-stage configuration. Because current density has a first-order impact on thruster wear due to sputter erosion, the two-stage scheme offers potential lifetime improvements over singlestage Hall thrusters.

\section{VHITAL Technology Assessment and Status}

From 2005 to 2006, the VHITAL-160 thruster was fabricated and tested by TsNIIMASH Export in Russia. Thermal analysis verified that the thruster design will ensure self-heated operation at the $25-\mathrm{kW}$ and $36-\mathrm{kW}$ operating points. Functional testing of the VHITAL-160 thruster at TsNIIMASH demonstrated 25-kW and 36-kW steady state operation, meeting the objectives of the VHITAL program. The thruster is scheduled to be shipped to the Jet Propulsion laboratory for functional tests in the fall of 2006.

\subsection{Advanced Lithium-Fed Applied-field Lorentz Force Accelerator (ALFA $\left.{ }^{2}\right)^{1}$}

The ALFA ${ }^{2}$ program was one of two proposals selected by NASA's Prometheus Project for funding in response to the Advanced Electric Propulsion solicitation in FY05. The $\mathrm{ALFA}^{2}$ team was led by Princeton University and included the Jet Propulsion

\footnotetext{
${ }^{1}$ James Polk, NASA Jet Propulsion Laboratory (james.e.polk@jpl.nasa.gov)
} 
Laboratory (JPL), the Marshall Spaceflight Center (MSFC), the Glenn Research Center (GRC), the University of Michigan (UM), Worcester Polytechnic Institute (WPI) and

Aerojet. The objective of $\mathrm{ALFA}^{2}$ was to develop a next-generation lithium-fed, appliedfield magnetoplasmadynamic thruster (AF-MPDT) with a power level of $245-250 \mathrm{~kW}$, efficiency of $60-63 \%$, a specific impulse of $6,200 \mathrm{~s}$ and the 3 year lifetime specified by the solicitation. The base period program focused on the design of a laboratory model thruster and lithium feed system, and the conceptual design of a flight-likè system. The ultimate goal was to develop a robust and compact steady-state thruster that could benefit various high-power missions considered by Project Prometheus. The $\mathrm{ALFA}^{2}$ program leveraged MPDT research conducted over the past two decades at the Moscow Aviation Institute (MAI), Princeton University, and JPL, and advances in a number of critical technology areas were made prior to base period program completion in October, 2005.

\section{Advantages of Lithium-Fed MPD Thrusters}

As discussed in Section 2.2, MPD thrusters utilize the electromagnetic Lorentz force to accelerate plasma. In steady-state operation, high currents with radial and axial components formed between an inner cathode and an outer concentric anode produce a self-induced azimuthal magnetic field, the combination of which generates thrust by the Lorentz force. An applied-field MPDT such as ALFA ${ }^{2}$ exploits additional thrust generating mechanisms by introducing an externally-applied magnetic field with radial and axial components. Lithium-fueled MPDTs have the unique and demonstrated ability to efficiently process very high power in a single compact thruster (over $50 \%$ efficiency and up to $500 \mathrm{~kW}$ demonstrated steady-state), as well as produce steady-state thrust-to- 
power exceeding $20 \mathrm{~N} / \mathrm{MW}_{\mathrm{e}}$, provide specific impulses exceeding $4,000 \mathrm{~s}$, and generate thrust densities above $200 \mathrm{~N} / \mathrm{m}^{2}$.[54]

Li propellant enables this high performance with uniquely low frozen flow losses. The ionization energy is very low $(5.39 \mathrm{eV})$ and the first excited state and second ionization potential energies are high, so little power is consumed in ionizing the propellant or lost in multiply-charged ions. Also, as a significant benefit for high-power ground tests; lithium condenses on inexpensive, water-cooled vacuum chamber surfaces and does not need to be pumped out of the chamber, which reduces facility pumping requirements by orders of magnitude compared to noncondensable gas propellants. For future long duration life tests, the Li propellant can be recycled with a closed loop purification system, similar to those already demonstrated in closed loop power conversion test facilities with other alkali metals (e.g., sodium). Li propellant can be compactly stored as a solid at room temperature, reducing the mass of propellant tanks. $\mathrm{Li}$ is delivered to a vaporizer in the thruster as a low-pressure liquid, which enables the use of electromagnetic feed system components with no moving parts. The availability of Li relative to xenon propellant (presently about 12,000 metric tons [MT] per year $\mathrm{Li}$ production compared to $35 \mathrm{MT} / \mathrm{year}$ Xe production) may be an important discriminator for missions with heavy payloads that require large propellant loads. Finally, because lithium is a good neutron moderator the propellant may provide significant radiation shielding in NEP applications, reducing the mass of reactor shielding required.

The high power density of magnetoplasmadynamic thrusters yields a number of potential flight system benefits compared to xenon ion engines, including significantly reduced volume for configuration and packaging of thrusters, reduced propulsion system 
complexity and parts count (PPUs, feed system components, etc.), and lower propulsion system mass. Steady-state operation greatly simplifies propellant feed and power systems, and enhances robustness and reliability. Further discussion of potential benefits is included in Section 5 below.

\section{$\underline{\text { ALFA }^{2} \text { Thruster Design }}$}

A critical review of the state-of-the-art in MPDT technology [54] revealed the best performance was obtained using lithium propellant, with thrust efficiencies of $50-69 \%$ at specific impulses in the 4000-5500 s range, respectively. At the high power levels of relevance to the $\mathrm{ALFA}^{2}$ project, the highest steady-state lithium MPDT performance to date was obtained with the MAI-200, which demonstrated an efficiency of $48 \%$ with an Isp of $4250 \mathrm{~s}$ at the peak power of $192 \mathrm{kWe}$. The projected performance of the $\mathrm{ALFA}^{2}$ thruster is a significant improvement over this state of the art, but it is consistent with previously measured performance trends.

A coordinated research program on Li-MPDTs at MAI, Princeton and JPL from 19942003 was leveraged in the detailed design of the ALFA ${ }^{2}$ thruster, shown schematically in Fig 7 . The thruster consists of a central cathode assembly with an integrated heater and lithium vaporizer, surrounded by a cylindrical anode assembly and two water-cooled electromagnets that provide the applied magnetic field. The anode and cathode assemblies are bolted to two bus plates separated by a main insulator. For ease of fabrications, the thruster design exploits manufacturing techniques developed at MAI, Princeton and JPL.

The thruster geometry was designed to meet the performance requirements within constraints imposed by the lifetime requirements. Critical geometry and operating 
parameters were selected using a detailed semi-empirical model and other scaling relations.[55-59] These relations were developed at MAI from a performance database [60-62] obtained with three laboratory model applied-field Li-MPDTs operated at 30 $\mathrm{kWe}, 120 \mathrm{kWe}$, and $200 \mathrm{kWe}$. The scaling relations show outstanding accuracy in predicting performance (within $4 \%$ in most cases). The nominal ALFA ${ }^{2}$ design point was chosen to be safely inside the region of parameter space that satisfies the solicitation requirements while remaining as close to the previous state of the art design as possible. The $\mathrm{ALFA}^{2}$ electrode designs were based on models of electrode wear [63] and were sized to meet stated performance requirements, with operating temperatures consistent with long life. Preliminary thermal modeling showed acceptable temperatures on the rest of the thruster assembly. A throttling analysis demonstrated that although the ALFA thruster was optimized to provide an Isp greater than $6000 \mathrm{~s}$ at $60 \%$ efficiency when operate at $250 \mathrm{kWe}$, the thruster could also be operated over a lower Isp range of 4500 $5000 \mathrm{~s}$ and still maintain high efficiency (56-58.8\%) at high power levels (200-235 kW). Optimizing the $\mathrm{ALFA}^{2}$ design for these lower operating points would provide even higher thruster efficiency for missions requiring lower specific impulse values.

\section{Lithium Vaporizor and Feed System}

Significant progress in the understanding of the two-phase flow in the lithium vaporizer was made during the base period of the $\mathrm{ALFA}^{2}$ program. The vaporizer was modeled initially using a 1-D, thermal-resistive network [64] and subsequently with a thermal-fluid model [65] using commercially available FLUENT software to calculate the required vaporizer length and power as a function of mass flow rate, channel geometry, and material properties. In the thermal resistive network model the radial 
temperature distribution through the vaporizer tube and two- phase lithium fluid is solved as a function of distance along the channel. The model was validated by comparison to existing preheat power data for the MAI $200 \mathrm{kWe}$ thruster. The cold-start heater power for the $\mathrm{ALFA}^{2}$ operating point was found to range from 3.38 to $3.60 \mathrm{~kW}$, corresponding to a vaporizer (axial) length of 18 to $26 \mathrm{~cm}$. The strongest drivers of vaporizer performance are cathode tube emissivity and the conduction heat flow path through the mounting flange. For the baseline case, increasing the vapor superheat from $100 \mathrm{~K}$ to 300 $\mathrm{K}$ has the effect of lowering the thermal efficiency from $57 \%$ to $49 \%$. The majority of the pressure drop is found to occur in the fully vaporized portion of the channel and ranges from approximately $2.5-7 \mathrm{kPa}$ for the range of flow rates of interest.

A prototype lithium feed system design based on previous experience at MSFC with Bi feed systems [66] was developed for the $\mathrm{ALFA}^{2}$ thruster. A prototype electromagnetic pump was built, and successfully pumped lithium at an estimated flow rate of about one gram per second with twenty amps of driving current. A prototype electromagnetic flow sensor was also constructed, and volume flow rates consistent with the ALFA ${ }^{2}$ requirements were measured with approximately five percent uncertainty. These tests demonstrate the feasibility of building low mass liquid metal feed systems with no moving parts for lithium-fed thrusters.

\section{ALFA ${ }^{2}$ Vehicle Study}

Trade studies on vehicle configuration leading to the definition of a candidate vehicle design were conducted to help guide the technology development and provide performance and mass estimates for mission analyses. A system functional block diagram was developed to identify all major spacecraft systems that were to be included in the 
system model. A conceptual flight thruster design with a configuration traceable to $\mathrm{ALFA}^{2}$ lab thruster design was developed. The primary differences include radiationcooled solenoids and flight packaging. A conceptual flight lithium feed system design with components traceable to the ALFA ${ }^{2}$ feed system development but with the redundancy required for a flight system and a conceptual power processing unit design were also developed. These conceptual subsystem designs were then used to create a detailed mass and power list that was used in the mission benefits analysis. The conceptual system design demonstrated that high power NEP vehicles can be configured to accommodate the ALFA ${ }^{2}$ propulsion system. The conceptual subsystem design choices from the trade studies represent relatively low risk approaches that satisfy mission requirements. Finally, very detailed mass and power lists integrated with mission analyses yielded a good picture of $\mathrm{ALFA}^{2}$ mission benefits, as described in Section 5 below.

As part of the vehicle configuration study the potential for spacecraft contamination from the condensable lithium vapor plume was assessed [67]. This included an analysis of the maximum tolerable flux of lithium to a nuclear reactor radiator surface and plume modeling to determine if fluxes exceeded these levels. The plume model employed estimates of the plasma properties at the exit of the thruster and a hybrid particle-fluid code developed at $\mathrm{UM}$, which was modified to include collision cross sections for the lithium plasma. Several plume shield configurations were modeled directly in the simulations. The simulations indicated that the $\mathrm{ALFA}^{2}$ thruster will produce plume backflow, but demonstrated that the spacecraft can be adequately protected by plume shields. 
In summary, the ALFA ${ }^{2}$ base period effort resulted in a solid foundation for the thruster design and integration into a high power vehicle. Subsequent development efforts would focus on demonstration of the projected performance and life of the thruster and associated subsystems.

\subsection{Nuclear Electric Pulsed Inductive Thruster (NuPIT) ${ }^{1}$}

The Pulsed Inductive Thruster (PIT) is an electromagnetic thruster invented at TRW (now Northrop Grumman Space Technology, or NGST) in the mid 1960's. Intermittent development of the PIT continued at TRW/NGST over the next several decades.[68-70] In 2004, the NASA Prometheus project awarded "The Nuclear-Electric Pulsed Inductive Thruster (NuPIT)" contract to NGST to further develop a high power pulsed inductive thruster. As discussed previously, the PIT (Fig 8) generates an electrodeless, inductively coupled plasma discharge. The TRW PIT Mark-V was operated in single-shot mode, and with ammonia propellant produced a nominal impulse bit of approximately $0.1 \mathrm{~N}-\mathrm{s}$ at a discharge energy of 4-kJ. Specific impulse ranged from $2000 \mathrm{~s}$ to $8000 \mathrm{~s}$ over a fairly flat efficiency range of $42-54 \%$, with the peak thruster efficiency occurring at an Isp of approximately $5000-\mathrm{s}$. Material erosion issues are mitigated by the electrodeless nature of the discharge, and thrust and specific impulse can be tailored by adjusting the pulse repetition rate and propellant mass injection, respectively.

The NuPIT program consisted of three complementary efforts. The primary effort was a hardware development and test program performed by NGST.[71] Detailed NuPIT mission analysis was provided by JPL [72], and magnetohydrodynamic modeling of

\footnotetext{
${ }^{1}$ Derrek Russell, Northrop Grumman Space Technology (derrek.russell@ngc.com)
} 
NuPIT performance was performed by the Arizona State University (ASU) [73]. The NuPIT program consisted of a base period and three option periods. The base period was completed in September 2005.

\section{NuPIT Experimental Development}

The hardware development and test program under the NuPIT contract focused on developing the Mark VII version of the PIT. The Mark VII thruster differs from previous PIT designs in the use of solid state switches rather than spark gaps to discharge the capacitor bank, with continuous planned operation at up to 50 pulses per second at a total power of $200 \mathrm{~kW}$. The advantages of solid state switches over spark gaps include much longer switch lifetime and turn-off capability. This makes it possible to "trap" residual electrical energy in the capacitor bank that would otherwise ring down inside the inductor coil after the propeliant has been expelled. The ability to recover this unutilized electrical energy may increase PIT thrust-efficiency to $70 \%$. To achieve this efficiency improvement, the solid state switches must be able to turn off a load current of several thousand Amps before the beginning of the third half-cycle of current, which starts only a few microseconds after firing.

The NGST development and test program selected several candidate solid state switches, and tested them on a load that simulated the load of the PIT. One switch type was a silicon controlled rectifier (SCR); two other switches were gate commutated thyristors (GCTs). GCTs are more advanced devices that can turn on and off with gate current, whereas SCRs are turned on with gate current and turned off by reversing the load current. Separate gate-drive circuits were designed and built at NGST for the SCR 
and the two GCT switches. The switches were physically mounted to their gate drive circuits in order to limit the gate circuit inductance and minimize switching time.

The SCR devices developed internal shorts after only a few shots. The reason for these failures was not well understood, and the SCR switch effort was terminated. The GCT switches yielded better results. Turn-off before the onset of the third half-cycle was achieved at $1 / 3$ and $1 / 2$ the full PIT load current. However, the devices again failed shortly after test. A failure analysis revealed that failure was caused by excessive gate current, exacerbated by non-uniform clamping. Subsequent turnoff attempts at the full PIT load current also resulted in device failures. The primary finding of the solid state switch tests was that turn-off of the full PIT load current before the onset of the third half-cycle of current could likely be accomplished with larger GCTs rated for larger gate current. GCTs rated for gate currents five times larger than that of the GCT devices used in this test are commercially available, and future development of the PIT hardware will focus on building integrated stacks of these larger GCT devices and their gate-drive circuits.

\section{NuPIT Mission Analysis}

As part of the NuPIT development effort, the NASA Jet Propulsion Laboratory analyzed the use of high power NuPIT engines for primary propulsion on several candidate missions. Based on preliminary estimates of future PIT technology capabilities, the analysis determined that the PIT propulsion system can provide mission performance comparable to that of advanced ion and hall thruster systems for several potential NEP missions. Compared to ion engines, the use of the higher power PIT provides nearly an order-of-magnitude reduction in the number of required thrusters, with a corresponding 
reduction in propellant storage and feed system parts count. This reduction in system complexity may ultimately prove more attractive than NuPIT mass or trip time benefits by allowing the implementation of a more reliable propulsion system. Additional details arising from the JPL study are included in Section 5 below.

Another significant benefit arising from the JPL mission studies is the unique ability of the PIT to use a variety of propellants without significant hardware changes, which offers the potential to use propellants derived from extraterrestrial resources. Of particular interest is water, which is expected to yield similar performance to previously demonstrated ammonia propellant. The use of an efficient water-propellant PIT would make it possible to operate a reusable Mars cargo vehicle with the same initial mass as a one-way (disposable) vehicle, assuming water for the return trip is available in Mars orbit (e.g. from the Mars moon Phobos).

\section{NuPIT Numerical Modeling}

In support of the NuPIT design effort, the Arizona State University focused on advanced numerical simulations of high power PIT performance. The magnetohydrodynamic (MHD) computer code, MACH2, was previously used by ASU to simulate and understand PIT acceleration and energy deposition processes for helium and argon propellants at energy levels below $2000 \mathrm{~J} .[73]$ The code successfully captured magnitudes and trends of previous experimental impulse measurements, and a quantitative analysis of energy deposition provided useful insights regarding thruster performance. The more recent NuPIT modeling effort concentrated on upgrading the MACH2 code to model the PIT with ammonia propellant. ASU developed a thermochemical model (equation of state) that incorporated the thermodynamic 
properties of $\mathrm{NH}_{3}$ over the wide range of temperature and pressure values expected during PIT operation.[74] The thermochemical model has allowed ASU to begin realistic simulations of the PIT engine operated with ammonia propellant. In addition to ammonia, future PIT simulations will focus on MACH2 modeling with potential in-situ resource propellants such as methane, carbon dioxide, and water.

\section{NUCLEAR ELECTRIC PROPULSION MISSIONS ANALYSIS ${ }^{1}$}

A number of outer solar system NEP robotic exploration missions were considered by the NASA Prometheus project office as potential follow-on missions beyond the Jupiter Icy Moons Orbiter mission. Typically, because of the need for short trip times to these distant destinations, the mission $\Delta \mathrm{Vs}$ and NEP total or "bus" power levels are significantly higher than those anticipated for the JMO mission. Although intended for high-power NEP robotic planetary exploration applications, these high-power NEP systems could also be used for electric propulsion Cargo missions supporting Human exploration of the Moon or Mars.

Two potential post-JIMO NEP outer solar system science missions were selected for study by JPL. The mission $\Delta \mathrm{V}$ range spanned from approximately $35-\mathrm{km} / \mathrm{s}$ to $60-\mathrm{km} / \mathrm{s}$. The first mission selected was a Saturn Orbiter with Moon Tour; the total required $\Delta V$ is approximately $41 \mathrm{~km} / \mathrm{s}$, depending on the mission specific impulse, acceleration, and trip time. The second mission was an Interstellar Precursor to 200 astronomical units (AU), with a solar system escape velocity of either 5-AU/year (total $\Delta \mathrm{V}$ of approximately $35-$ $\mathrm{km} / \mathrm{s}$ ) or $10-\mathrm{AU} / \mathrm{Year}$ (total $\Delta \mathrm{V}$ requirement of about $60-\mathrm{km} / \mathrm{s}$ ). Also selected were two

\footnotetext{
${ }^{1}$ Robert Frisbee, NASA Jet Propulsion Laboratory (robert.h.frisbee@jpl.nasa.gov)
} 
lower- $\Delta \mathrm{V}$ (but much larger payload) inner solar system cargo delivery missions that could be used to support human exploration of the Moon (round trip $\Delta \mathrm{V}$ of approximately $16-\mathrm{km} / \mathrm{s}$ ) or Mars (one-way $\Delta \mathrm{V}$ of roughly $16-\mathrm{km} / \mathrm{s}$ ).

A spreadsheet-based systems-level model was developed for high-power NEP vehicles encompassing $\mathrm{MW}_{\mathrm{e}}$-class robotic missions. A near-term advanced xenon (Xe) propellant ion thruster was used as a basis for comparison to three advanced-technology electric propulsion thrusters: the ammonia $\left(\mathrm{NH}_{3}\right)$ propellant $\mathrm{NuPIT}$, the lithium (Li) propellant $\mathrm{ALFA}^{2}$, and the bismuth (Bi) propellant VHITAL. The special case of a water $\left(\mathrm{H}_{2} \mathrm{O}\right)$ propellant NuPIT system, using water derived from extraterrestrial resource utilization (ETRU), was also considered. The modeling tool allowed he investigation of various vehicle performance trades based on thruster specific impulse, efficiency, power-perthruster, lifetime (propellant throughput), propellant storage and feed system mass and complexity (i.e., parts count), and the necessity for plume shields when using condensable propellants like $\mathrm{Li}$ and $\mathrm{Bi} .[53,72,75]$

Based on projected estimates of future ion thruster, NuPIT, ALFA ${ }^{2}$, and VHITAL technology capabilities, it was found that all four systems have similar mass and trip time performance. This is illustrated in Fig 9, where the relative initial mass in low Earth orbit (IMLEO) and trip time of the various propulsion options (plus the special case of NuPIT using ETRU water) are compared to the ion thruster system in terms of decreasing mission "difficulty" (a function of mission $\Delta \mathrm{V}$ and payload). For the more difficult high$\triangle \mathrm{V}$ NEP science missions, the NuPIT and ALFA ${ }^{2}$ systems typically have a modest mass or trip time increase compared to an advanced ion thruster system. By contrast, the VHITAL system, with its lighter propellant tankage (due to its use of high-density Bi 
propellant), has modestly superior mission performance. Finally, the projected long lifetime (high throughput) of the ion thruster is advantageous for missions with a very high total propellant load. Otherwise, additional complete sets of thrusters are needed in order to consume all of the mission propellant. For example, the dashed lines in Fig 9 correspond to cases where the NuPIT, ALFA ${ }^{2}$, or VHITAL thruster's throughput is increased so that only one set of thrusters is required. Thus, for the $10-\mathrm{AU} / \mathrm{Year}$ interstellar precursor mission, the NuPIT throughput would need to be increased by a factor of 1.47 over its projected value, a factor of 2.75 for $\operatorname{ALFA}^{2}$ (1.45 for the Saturn mission), and a factor of 1.09 for VHITAL. The case for VHITAL also illustrates the somewhat paradoxical result that throughput-per-thruster is less of an issue for thrusters with a modest power-per-thruster, because many thrusters (e.g., several tens of thrusters) are running at $\mathrm{MW}_{\mathrm{e}}$ power levels. By contrast, the $\mathrm{ALFA}^{2}$ is most sensitive to low throughput because a very few number of thrusters are running, each with a modest throughput-per-thruster.

Also observed is a general trend that as mission "difficulty" decreases, the three advanced-technology systems tend to have slightly better performance relative to the ion thruster system. For example, the modest propellant loads and the need for low $\mathrm{I}_{\mathrm{sp}}$ (to maximize thrust) for the lunar cargo mission results in all three of the advancedtechnology propulsion systems demonstrating better mission performance than the advanced ion system. In addition, it is seen that the potential ability of the NuPIT thruster to use ETRU water propellant from the Moon or Mars can result in dramatic savings in IMLEO and trip time if water propellant is available in orbit for the return trip. Fig 9 also illustrates the relative trip time performance of the various propulsion options compared 
to the ion thruster system. For this comparison, the trip time of the ion thruster system (at the indicated mission trip time) is divided by the trip time of the other options for the case where they have the same IMLEO as the ion system.

Another important element of mission feasibility is the overall system "complexity," as quantified in this study by a parts count for the propellant storage and feed system, plus the number of thrusters and PPUs. Fig 10 illustrates the relative parts count of the various thruster options, again relative to the ion thruster system. For all missions examined, the inherently high power-per-thruster of the NuPIT and ALFA ${ }^{2}$ thrusters can result in nearly an order-of-magnitude reduction in the number of thrusters compared to the inherently low power-per-thruster ion engine.

There is also the issue of the "complexity" of volumetrically packaging and integrating a large number of thrusters so that they fit within the constraints of a launch vehicle payload shroud. For example, as shown in Fig 11, it may not be possible to accomplish a $\mathrm{MW}_{\mathrm{e}}$-class NEP mission with an ion system simply because the number of required thrusters exceeds the number that can realistically fit into the payload shroud of the launch vehicle. Thus, the high power-per-thruster NuPIT and in particular ALFA ${ }^{2}$ systems are potentially much easier to integrate and package simply because of the smaller number of thrusters. Even the VHITAL system, which may have only a moderately higher power-per-thruster than the ion thruster (depending on $\mathrm{I}_{\mathrm{sp}}$ ), can still be easier to package than an ion system because of the VHITAL thruster's higher power density. The reduction in parts count and simpler packaging of the NuPIT, ALFA ${ }^{2}$, and VHITAL systems may ultimately prove more attractive than their potential mass or trip time benefits, allowing the implementation of a more reliable propulsion system with 
much simpler demands on system integration, testing, and packaging into a constrained launch vehicle payload shroud volume.

Based on the results of these analyses, the general conclusion is made that no single advanced electric propulsion technology is "best" for all combinations of missions, masses, trip times, specific impulses, power levels, payload masses, etc. It is emphasized that the results presented here show only the potential impact of the various technologies on mission performance; these results are based on assumed improvements over state-ofthe-art thruster performance and lifetime. These improvements must yet be demonstrated in the laboratory to validate the mission advantages shown here, and to provide the technology base that will enable bold new robotic and human exploration of the solar system. Further mission analyses using updated performance parameters should be performed as new information becomes available from thruster research programs to provide a higher fidelity assessment of the relative benefits presented here.

\section{STATUS OF NUCLEAR SPACE POWER SYSTEMS ${ }^{1}$}

Nuclear fission systems for space power applications have been of interest for several decades. Potential applications include the provision of uninterrupted power on the surface of the moon, Mars, or asteroids, and as power sources for nuclear electric propulsion systems. Internationally, several billion dollars have been spent over the years developing and testing nuclear space power systems, and to date thirty-four systems have flown. These include the United States SNAP-10A, two Russian TOPAZ-1 systems, and thirty-one Russian BUK systems.[76,77]

\footnotetext{
${ }^{1}$ Michael Houts, NASA Marshall Space Flight Center (michael.ghouts@nasa.gov)
} 
Present interest in space fission systems is focused on fission surface power (FSP). If developed, FSP systems could potentially enable power-rich environments anywhere on the surface of the moon, Mars, or elsewhere in the solar system. Such systems would be particularly useful where solar power is difficult to access or is unavailable for long periods of time. An informal survey of previously published studies shows that FSP module sizes of $10 \mathrm{kWe}$ to $50 \mathrm{kWe}$ would be optimal for initial lunar or Mars outpost applications. In this power range, fuel burn-up tends to be low, radiation damage to materials is minor, and well characterized materials such as 316-stainless steel can be used. Innovative test strategies can be devised to affordably obtain all data needed for FSP qualification, launch, and operation. A more detailed discussion on how these and other factors could help reduce the development cost of FSP systems can be found in Poston.[78] Fission surface power systems are also extensible to the very high power levels required to support the future evolution of lunar and planetary exploration.

As noted throughout this paper, fission reactors are also being considered as power sources for nuclear electric propulsion. The performance of NEP systems is strongly affected by the specific mass of the power supply. Power supply specific mass can be reduced by operating the reactor at high temperature and/or high power. High temperature reactor operation allows waste heat to be rejected at a relatively high temperature while maintaining high system efficiency. The combination of high system efficiency and high heat rejection temperature reduces radiator area and mass. Such high power operation allows economy of scale, particularly with respect to the reactor and power conversion subsystem. 
The most recent national program involving NEP was the NASA Jupiter Icy Moons Orbiter (JIMO), previously described in Section 3.1. A potential nuclear reactor concept considered for JMO used refractory-metal clad, highly enriched uranium dioxide fuel directly coupled to a Brayton power conversion subsystem. The Brayton turbine inlet temperature was approximately $1150 \mathrm{~K}$, with a significantly higher peak fuel clad temperature. Although the proposed JIMO power supply operated at a relatively high turbine inlet temperature, the pressure boundary was kept cool and conventional materials could be used to provide that boundary. Additional information concerning the JMO power supply design concept is found in Ashcroft.[79]

Although the current emphasis has shifted to fission surface power systems, sustained work in this area can also benefit the development of future nuclear electric propulsion systems. Design teams formed to develop FSP systems could readily be used in the design and development of NEP space power systems. The infrastructure associated with irradiating and examining fuels and reactor subcomponents is equally applicable to both FSP and NEP development. High fidelity non-nuclear test facilities can in general be used for the development, testing, and qualification of either type of power system. The facilities and equipment used for pre-launch processing and the launch of FSP systems could either be modified or used directly for NEP systems. Experience gained from the Assembly, Test, and Launch Operations (ATLO) process required for a fission surface power system launch would be directly applicable to the launch of NEP systems. As such, future NEP systems will clearly benefit from the ongoing efforts related to current fission surface power system development. 


\section{RADIOISOTOPE ELECTRIC PROPULSION ${ }^{1}$}

Prior sections of this paper discussed Nuclear Electric Propulsion (NEP), in which high power electric thrusters are coupled to onboard fission reactors. In counterpoint, this section reviews the status of Radioisotope Electric Propulsion (REP), which couples low power electric propulsion systems to onboard radioisotope power supplies.[80] REP systems are envisioned for potential use on small to medium-class science spacecraft that can effectively explore targets of opportunity in the outer solar system, using medium class launch vehicles to provide initial excess velocity from Earth.[81] Recently, Oleson and Fiehler have proposed to use the launch vehicle to achieve Earth escape on a parabolic heliocentric trajectory, and then use the REP system both to accelerate to a hyperbolic heliocentric trajectory and then to decelerate to capture around a target body.[82,83] By maximizing the initial velocity imparted by the launch vehicle, very rapid flight times can be achieved to targets in the outer solar system. The electric propulsion system allows trajectory modifications en route to the destination to enable capture into orbit around the target body. This concept puts the mass atop the launch vehicle at a premium, hence REP systems are highly sensitive to system $\alpha$ (ratio of mass to power). Techniques to minimize the $\alpha$ of REP systems have been studied at Aerojet and General Dynamics - Electric Boat.[84] The desired approach maximizes the power output for a given quantity of thermal energy by minimizing the conversion steps required to provide power to the EP thruster. System $\alpha$ will be minimized for these conditions due to the reduction in power conversion mass and the associated thermal control mass required to dissipate waste heat. Fig 12 illustrates this approach. The top

\footnotetext{
${ }^{1}$ R. Joseph Cassady, Aerojet Redmond Operations (joe.cassady@rocket.com)
} 
portion of the figure shows the overall system performance using a conventional power conversion approach. An optimized power conversion approach using Stirling generators and direct drive electric propulsion is shown in the lower portion of the figure. The conversion efficiencies and power loss in watts are shown for each approach to aid in the comparison. It is seen that direct drive systems can offer significant savings in terms of input power and associated mass compared to conventional power conversion schemes. Direct drive systems will be discussed in more detail later in this section.

Another distinguishing characteristic of an REP system is that it requires less than half the mission delta $\mathrm{V}$ of a high power solar or nuclear electric propulsion system. The optimal $\mathrm{I}_{\mathrm{sp}}$ is consequently lower for REP missions, and could be met by current or near term electric thrusters. However, most REP missions envision operating at system power levels of $500-\mathrm{W}_{\mathrm{e}}$ to $1000-\mathrm{W}_{\mathrm{e}}$, and challenges arise in scaling down current $\mathrm{EP}$ thrusters to operate efficiently at these lower powers. Although current ion and Hall-effect thrusters could be used for these missions, they are at present optimized to operate at much high powers.

\subsection{REP Power Systems}

Over the past several years, NASA and the U. S. Department of Energy (DOE) have been developing new RPS systems for potential use on future planetary missions.[85] Efforts are proceeding in two primary directions: development of an advanced MultiMission Radioisotope Thermal Generator (MMRTG), and development of a dynamic, high efficiency Stirling Radioisotope Generator (SRG). Both systems rely on the Department of Energy's General Purpose Heat Source (GPHS) to provide heat. GPHS modules have been used as the basic building blocks for GPHS-Radioisotope 
Thermoelectric Generator (RTG) power systems that were used on the Galileo, Cassini, and New Horizons missions. The GPHS modules are integral to future RPS designs such as the SRG.

Because the specific mass of the power system decreases with increasing conversion efficiency, REP systems favor the use of higher efficiency thermal-to-electrical power conversion devices. As such, the Stirling Radioisotope Generator has received considerable attention. A Stirling engine is used to drive a linear alternator attached to a piston, which in turn produces a sinusoidal voltage output on the power bus. For REP applications, this $\mathrm{AC}$ voltage can be increased by tapping off the alternator and summing the outputs with a slight phase shift. This stacked converter approach has been investigated for non-space applications by General Dynamics - Electric Boat; the advantage for REP space missions is that a stacked converter can provide a higher voltage more nearly matched to the EP thruster operating voltage. Extensive testing over the past several years has retired key SRG power system risk areas, such as system life and vibration. [86,87] If sufficient funds were made available, the SRG program could be flight ready by the 2009-2010 timeframe.

\subsection{Direct Drive EP}

In the late 1990 s, Hamley et al. demonstrated that Hall-effect thrusters could be stably operated directly from high voltage solar arrays.[88] Under NASA funding, Aerojet Corp developed a bread-board power processing unit (PPU) that demonstrated $300-\mathrm{V}$ solar array compatibility with a $5-\mathrm{kW}$ Hall thruster running at full power in direct drive mode.[89] This effort demonstrated that a majority of the mass and nearly all of the thermal dissipation can be eliminated from the PPU in a direct drive system. Of the major 
components of a conventional PPU, the main power converters and their control circuits are completely eliminated. Other components would stay basically the same, including the heater keeper magnet supply, auxiliary power supply, xenon flow control drivers, and remaining control electronics. Standard and direct drive Hall thruster PPU input and output filters will remain similar, in particular input filtering for the heater keeper magnet supply, auxiliary power supply, and output filtering to the thruster. By using direct drive, the PPU board area is reduced approximately $50 \%$. Because power converters are significantly heavier than control circuits, direct drive PPU mass savings are expected to approach $65 \%$. Similar savings are expected for a direct drive ion engine PPU.

\subsection{REP Mission Benefits}

Radioisotope electric propulsion can truly be enabling for the high priority NASA planetary missions identified in National Research Council Decadal Survey.[90] The 2006 launch of the New Horizons mission to Pluto will complete the survey of the classical outer planets via flyby encounters. The next step is to study these objects in more detail via planetary orbiter missions. A small spacecraft that combines a radioisotope power system (RPS) with electric propulsion makes affordable outer planet orbiters a reality. As shown by Oleson et al [91], REP missions launched with an Atlas 551 launch vehicle can deliver between $150 \mathrm{~kg}$ and $300 \mathrm{~kg}$ of non-power and propulsion payload mass to orbits around Saturn, Uranus, Neptune and Pluto with trip times ranging from 5-years to 15-years, depending on spacecraft mass and destination. Fig 13 presents study results comparing REP system trip times for various outer planet destinations.

A major benefit provided by REP is the relaxation of mission launch opportunity constraints. For many currently envisioned chemically propelled orbiter missions to the 
moons of Jupiter or Saturn, multiple planetary gravity assist flybys are necessary. This requires precise timing of the launch to ensure planetary alignment for the flybys. REP missions, on the other hand, are direct flights to the targets; no gravity assists are used. The only timing constraints placed on the launch of an REP mission are those having to do with the relative positions of Earth and the destination body.

An additional benefit of using a radioisotope power system is that the waste heat can be used to heat propellant lines, instruments, and other temperature sensitive devices onboard the spacecraft. Pantano et al have shown that a high efficiency SRG can reject heat at lower temperatures than an RTG system, which allows direct heating of spacecraft elements using heat pipes or other means.[92] RTG systems used on current spacecraft, such as Cassini, employ lower efficiency thermoelectric conversion devices that reject heat at $200{ }^{\circ} \mathrm{C}$ versus the nominal $50^{\circ} \mathrm{C}$ used in advanced SRG systems. The higher heat rejection temperature requires a complex coupling between heat source and spacecraft in order to provide useful heat to the spacecraft without overheating. As a result, most RTG missions place the heat sources on extended booms to improve heat radiation and keep unwanted waste heat from the spacecraft.

In summary, Radioisotope Electric Propulsion systems can provide significant benefits for future planetary science missions. Power system specific mass can be substantially reduced by eliminating heavy PPU electronics and thermal control hardware, and the combination of advanced SRG development with direct drive electric propulsion could enable several high priority robotic science missions. 


\section{CONCLUDING REMARKS}

The benefits of using electric propulsion for in-space transportation are well known, and the coupling of electric propulsion with fission and radioisotope space power systems would provide new capabilities for robotic and human exploration of the solar system. Over the past few years, the NASA Prometheus Power and Propulsion Office funded the development of high power electrostatic and electromagnetic thruster systems that could revolutionize future space transportation. Sponsored projects included the fabrication and testing of high power HIPEP and NEXIS gridded ion thrusters for use on the presently cancelled Jupiter Icy Moons Orbiter mission; the fabrication and testing of the dual stage, bismuth-fed VHTAL high specific impulse Hall-effect thruster; the development of the high power $\mathrm{ALFA}^{2}$ electromagnetic thruster designed for steady-state operation with lithium propellant; and the testing of pulsed high power, high repetition rate switching components for the electrodeless NuPIT electromagnetic thruster. Detailed mission analysis was used to identify several high priority missions of interest that benefit from the use of high power NEP systems, ranging from multiple rendezvous and orbit within planetary systems, to cargo transport in support of future human lunar and Mars exploration. Smaller REP systems that couple radioisotope sources to low power electric thrusters have been designed for use on other equally demanding robotic science missions. Although current nuclear and radioisotope electric propulsion development efforts have been curtailed in favor of near-term exploration goals, the technology advancements summarized in this paper provide a solid foundation for the further development and future flight of these bold new space transportation systems. 


\section{ACKNOWLEDGEMENTS}

The authors thank Mr. John Warren, Mr. Jay Jenkins and Ms. Victoria Friedensen of the NASA Prometheus Power and Propulsion Office for their support of high power electric thruster development. Additionally, we thank the several electric propulsion engineers, researchers, and technicians within NASA, industry and academia, upon whose work this paper is based.

\section{REFERENCES}

[1] Moeckel WE. Propulsion systems for manned exploration of the solar system. NASA TM-X-1864; 1969.

[2] Jahn RG. Physics of electric propulsion. New York: McGraw Hill; 1968.

[3] Sovey JS, Hamley JA, Patterson MJ, Rawlin VK, Myers RM. The evolutionary development of high specific impulse electric thruster technology. Proceedings of the Space Programs and Technologies Conference, Huntsville AL USA; 1992, AIAA-92-1556.

[4] Choueiri EY. A critical history of electric propulsion: the first 50 years (19061956). J Propulsion and Power 2004; 20:193-203.

[5] Leiter H, Killinger R, Bassner H, Müller J, Kukies R, Fröhlich T. Evaluation of the performance of the advanced $200 \mathrm{mn}$ radio-frequency ion thruster RIT-XT.

Proceedings of the 38th AIAA/ASME/SAE/ASEE Joint Propulsion Conference and Exhibit, Indianapolis IN USA; 2002, AIAA-2002-3836.

[6] Kuninaka H, Shimizu Y, Yamada T, Funaki I, Nishiyama K. Flight report during two years on Hayabusa explorer propelled by microwave discharge ion engines. 
Proceedings of the 41st AIAA/ASME/SAE/ASEE Joint Propulsion Conference and Exhibit, Tucson AZ USA; 2005, AIAA-2005-3673.

[7] Kamhawi H, Foster J, Patterson M. Operation of a microwave electron cyclotron resonance cathode. Proceedings of the 40th AIAA/ASME/SAE/ASEE Joint Propulsion Conference and Exhibit, Fort Lauderdale FL USA; 2004, AIAA-20043819.

[8] Wilbur PJ, Rawlin VK, Beattie JR. Ion thruster development trends and status in the United States. J Propulsion and Power 1998; 14:708-15.

[9] Wilbur PJ, Beattie, JR, Hyman, J. An approach to the parametric design of ion thrusters. J Propulsion and Power 1990; 6:575-83.

[10] Gilland JH, Myers RM, Patterson MJ. Multi-megawatt electric propulsion system design considerations. Proceedings of the 21st International Electric Propulsion Conference, Orlando FL USA; 1990, AIAA-91-2552.

[11] Choueiri EY. Fundamental difference between the two Hall thruster variants. Phys. Plasmas 2001; 8:5025-33.

[12] Jankovsky RS, Tverdokhlebov S, Manzella D. High power hall thrusters. Proceedings of the 35th AIAA/ASME/SAE/ASEE Joint Propulsion Conference and Exhibit, Los Angeles CA USA; 1999, AIAA-99-2949.

[13] Gilland J. System level models of self- and applied-field MPD thrusters. Proceedings of the 40th AIAA/ASME/SAE/ASEE Joint Propulsion Conference and Exhibit, Fort Lauderdale FL USA; 2004, AIAA-2004-3470.

[14] Choueiri E, Ziemer K. Quasi-Steady magnetoplasmadynamic thruster performance database. J Propulsion and Power 2001; 17:967-76. 
[15] Polk JE, Kelley AJ, Jahn RG, Kurtz H, Auweter-Kurtz M. Mechanisms of hot cathode erosion in plasma thrusters. Proceedings of the 21st International Electric Propulsion Conference, Orlando FL USA; 1990, AIAA-90-2673.

[16] Hrbud I, LaPointe M, Vondra R, Dailey CL, Lovberg R. Status of pulsed inductive thruster research. In: El Genk M, editor. AIP conference proceedings 552, Space Technology and Applications International Forum -STAIF 2001, Melville NY: American Institute of Physics; 2001.

[17] Sercel J. ECR thruster research - preliminary theory and experiments. Proceedings of the $25^{\text {th }}$ AIAA/ASME/SAE/ASEE Joint Propulsion Conference and Exhibit, Monterey CA USA; 1989, AIAA-89-2379.

[18] Ilin A, Chang-Diaz F, Squire J, Carter M. Plasma heating simulation in the VASIMR system. Proceedings of the $43^{\text {rd }}$ Aerospace Sciences Meeting and Exhibit, Reno NV USA; 2005, AIAA-2005-949.

[19] Hack KJ, George JA, Riehl JP, Gilland JH. Evolutionary use of nuclear electric propulsion. Proceedings of the Space Programs and Technologies Conference, Huntsville AL USA; 1990, AIAA-90-3821.

[20] Barnett JW. Nuclear electric propulsion technologies: overview of the NASA/DOE/DOD nuclear electric propulsion workshop. In: El-Genk M, editor. AIP Conference Proceedings 246, Ninth Symposium on Space Nuclear Power Systems, Melville NY: American Institute of Physics; 1992.

[21] McGuire M, Martini MC, Packard TW, Weglian JE, Gilland JH. Use of high-power brayton nuclear electric propulsion (NEP) for 2033 Mars round trip mission. In: ElGenk M, editor. AIP conference proceedings 813, Space Technology and 
Applications International Forum STAIF-2006, Melville NY: American Institute of Physics; 2006.

[22] Metcalf K. Power conditioning system modeling for nuclear electric propulsion. NASA CR-191136; 1993.

[23] Oleson S, Katz I. Electric propulsion for project Prometheus. Proceedings of the 39th AIAA/ASME/SAE/ASEE Joint Propulsion Conference and Exhibit, Huntsville AL USA; 2003, AIAA-2003-5279.

[24] Request for Proposal: JIMO-2004 for Project Prometheus Jupiter Icy Moons Orbiter (JMO) Project. Jet Propulsion Laboratory, California Institute of Technology, CA USA; 2004.

[25] Sovey J, Hamley J, Haag T, Patterson M, Pencil E, Peterson T, Pinero L, Power J, Rawlin V, Sarmiento C. Development of an ion thruster and power processor for New Millenium's Deep Space 1 mission. Proceedings of the 33rd AIAA/ASME/SAE/ASEE Joint Propulsion Conference and Exhibit, Seattle WA USA; 1997, AIAA-97-2778.

[26] Elliot F, Foster J, Patterson M. An overview of the High Power Electric Propulsion (HIPEP) project. Proceedings of the 40th AIAA/ASME/SAE/ASEE Joint Propulsion Conference and Exhibit, Fort Lauderdale FL USA; 2004, AIAA-20043453.

[27] Foster J, Haag T, Kamhawi H, Patterson M, Malone S, Elliot F. The High Power Electric Propulsion (HIPEP) ion thruster. Proceedings of the 40th AIAA/ASME/SAE/ASEE Joint Propulsion Conference and Exhibit, Fort Lauderdale FL USA; 2004, AIAA-2004-3812. 
[28] Williams GW, Foster J, Hickman T, Malone S, VanNoord J. Performance Characterization of a $21-\mathrm{kW}$ high specific impulse ion thruster. Proceedings of the 41st AIAA/ASME/SAE/ ASEE Joint Propulsion Conference and Exhibit, Tucson AZ USA; 2005, AIAA-2005-4248.

[29] Farnell C. Numerical simulation of HIPEP ion optics. Proceedings of the 40th AIAA/ASME/SAE/ASEE Joint Propulsion Conference and Exhibit, Fort Lauderdale FL, USA; 2004, AIAA-2004-3818.

[30] Haag T. Mechanical design of carbon ion optics. Proceedings of the 41st AIAA/ASME/SAE/ASEE Joint Propulsion Conference and Exhibit, Tucson AZ USA; 2005AIAA-2005-4408.

[31] Williams GW, Haag T, Sovey J. Characterization of high-specific impulse, highpower ion optics. Proceedings of the 40th AIAA/ASME/SAE/ASEE Joint Propulsion Conference and Exhibit, Fort Lauderdale FL USA; 2004, AIAA-20043630.

[32] Williams GW. Life-limiting trends of high-specific impulse ion optics. Proceedings of the 40th AIAA/ASME/SAE/ASEE Joint Propulsion Conference and Exhibit, Fort Lauderdale FL USA; 2004, AIAA-2004-3627.

[33] Meckel N, Polaha J, Juhlin N. Structural analysis of pyrolytic graphite optics for the HIPEP ion thruster. Proceedings of the 40th AIAA/ASME/SAE/ASEE Joint Propulsion Conference and Exhibit, Fort Lauderdale FL USA; 2004, AIAA-20043629.

[34] Williams G, Haag T, Foster J, Van Noord J, Malone S, Hickman T, Patterson M. Results of the $2000 \mathrm{hr}$ wear test of the HIPEP ion thruster with pyrolytic graphite 
ion optics. Proceedings of the 42nd AIAA/ASME/SAE/ASEE Joint Propulsion Conference and Exhibit, Sacramento CA USA; 2006, AIAA-2006-4668.

[35] Williams G, Foster J, Miller J, Haag T, Fong D, Van Noord J, Malone S, Hickman T, Crable V, Patterson M. Wear-testing of a $21 \mathrm{~kW}, 7600 \mathrm{~s}$ ion thruster. Proceedings of the 41st AIAA/ASME/SAE/ASEE Joint Propulsion Conference and Exhibit, Tucson AZ USA; 2005, AIAA-2005-4396.

[36] Williams G, Haag T, Foster J, Van Noord J, Malone S, Hickman T, Patterson M. Analysis of the pyrolytic graphite ion optics following the 2000-hour wear test of the HIPEP ion thruster. Proceedings of the 42nd AIAA/ASME/SAE/ASEE Joint Propulsion Conference and Exhibit, Sacramento CA USA; 2006, AIAA-2006-5005.

[37] Wilson F, Hoskins A, Monheiser J, Meckel N, Aadland R, Polaha J. Overview of ion propulsion system development at Aerojet Redmond. Proceedings of the $40^{\text {th }}$ AIAA/ASME/SAE/ASEE Joint Propulsion Conference and Exhibit, Fort Lauderdale FL USA; 2004, AIAA-2004-3966.

[38] Randolph T, Polk J. An overview of the Nuclear Electric Xenon Ion System (NEXIS) activity. Proceedings of the 40th AIAA/ASME/SAE/ASEE Joint Propulsion Conference and Exhibit; Fort Lauderdale FL USA; 2004, AIAA-20043450.

[39] Polk J, Goebel D, Snyder J, Schneider A, Johnson L, Sengupta A. Performance and wear test results for a $20 \mathrm{~kW}$-class ion engine with carbon-carbon grids. Proceedings of the 41st AIAA/ASME/SAE/ASEE Joint Propulsion Conference ad Exhibit, Tucson AZ USA; 2005, AIAA-2005-4393. 
[40] Monheiser J, Polk J, Randolph T. Conceptual design of the Nuclear Electric Xenon Ion System (NEXIS). Proceedings of the 40th AIAA/ASME/SAE/ASEE Joint Propulsion Conference and Exhibit, Fort Lauderdale FL USA; 2004, AIAA-20043624.

[41] Vaughn J, Schneider T, Polk J, Goebel D, Ohlinger W, Hill D. NEXIS reservoir cathode 2000 hour proof-of-concept test. Proceedings of the 40th AIAA/ASME/SAE/ASEE Joint Propulsion Conference and Exhibit, Fort Lauderdale FL USA; 2004, AIAA-2004-4203.

[42] Banks B, Hung C, Walters P, Sechkar E, Gaier J, Karniotis C. Ultra high voltage propellant isolators and insulators for JMO ion thrusters. Proceedings of the 40th AIAA/ASME/SAE/ASEE Joint Propulsion Conference and Exhibit, Fort Lauderdale FL USA; 2004, AIAA-2004-3815.

[43] Anderson J, Katz I, Goebel D. Numerical simulation of two-grid ion optics using a $3 \mathrm{~d}$ code. Proceedings of the 40th AIAA/ASME/SAE/ASEE Joint Propulsion Conference and Exhibit, Fort Lauderdale FL USA; 2004, AIAA-2004-3782.

[44] Mikellides I, Katz I, Goebel D, Polk J. Theoretical model of a hollow cathode insert plasma. Proceedings of the 40th AIAA/ASME/SAE/ASEE Joint Propulsion Conference and Exhibit, Fort Lauderdale FL USA; 2004, AIAA-2004-3817.

[45] Katz I, Goebel D. Model of the plasma potential distribution in the plume of a hollow cathode. Proceedings of the 40th AIAA/ASME/SAE/ASEE Joint Propulsion Conference and Exhibit, Fort Lauderdale FL USA; 2004, AIAA-2004-4108. 
[46] Mikellides I, Johnson L, Katz I, Mandel M. A high power ion thruster plume model. Proceedings of the 40th AIAA/ASME/SAE/ASEE Joint Propulsion Conference and Exhibit, Fort Lauderdale FL USA; 2004, AIAA-2004-3816.

[47] Goebel D, Katz I, Watkins R, Jameson K. Hollow cathode and keeper-region plasma measurements using ultra-fast miniature scanning probes. Proceedings of the 40th AIAA/ASME/SAE/ASEE Joint Propulsion Conference and Exhibit, Fort Lauderdale FL USA; 2004, AIAA-2004-3430.

[48] Polk J, Marrese C, Dang L, Johnson L, Thornber B. Temperature distributions in hollow cathode emitters. Proceedings of the 40th AIAA/ASME/SAE/ASEE Joint Propulsion Conference and Exhibit, Fort Lauderdale FL USA; 2004, AIAA-20044116.

[49] Mikellides I; Katz I, Goebel D, Polk J. Theoretical modeling of a hollow cathode plasma for the assessment of insert and keeper lifetimes. Proceedings of the $41^{\text {st }}$ AIAA/ASME/SAE/ ASEE Joint Propulsion Conference and Exhibit, Tucson AZ USA; 2005, AIAA-2005-4234.

[50] Sengupta A, Brophy JR, Garner CE, Anderson JA. An overview of the results from the 30,000 hour life test of the Deep Space One flight spare ion engine. Proceedings of the 40th AIAA/ASME/SAE/ASEE Joint Propulsion Conference and Exhibit, Fort Lauderdale FL USA; 2004, AIAA-2004-3608.

[51] Sicard A, Bourdarie S. Physical Electron Belt Model from Jupiter's surface to the orbit of Europa. J Geophysical Research 2004; 109: A02216.1-A02216.13.

[52] Scina J, Hewitt F, Gerber S, Elbuluk M, Aulisio M, Miller L. Power processing for Prometheus electric propulsion systems. Proceedings of the 40th 
ALAA/ASME/SAE/ASEE Joint Propulsion Conference and Exhibit, Fort

Lauderdale FL USA; 2004, AIAA-2004-3452.

[53] Marrese-Reading,C, Sengupta A, Frisbee R, Polk J, Cappelli M, Boyd I, et al. The VHITAL program to demonstrate the performance and lifetime of a bismuth-fueled very high $\mathrm{I}_{\mathrm{sp}}$ hall thruster. Proceedings of the 41st AIAA/ASME/SAE/ASEE Joint • Propulsion Conference and Exhibit, Tucson AZ USA; 2005, AIAA-2005-4564.

[54] Kodys A, Choueiri E. A critical review of the state-of-the-art in the performance of applied-field magnetoplasmadynamic thrusters. Proceedings of the 41st AIAA/ASME/SAE/ASEE Joint Propulsion Conference and Exhibit, Tucson AZ USA; 2005, AIAA-2005-4247.

[55] Kim V, Tikhonov V, Semenikhin S. High power lithium-fed MPDT research. Fourth (Final) quarterly report on contract NASW-4851 between RIAME and JPL. RIAME MAI, Moscow; 1997.

[56] Kim V, Tikhonov V, Semenikhin S. High-power lithium-fed MPDT research. Second quarterly report on contract NASW-4851 between RIAME and JPL. RIAME MAI, Moscow; 1996.

[57] Tikhonov V, Semenikhin S, Alexandrov V, Dyakonov G, Popov G. Research of plasma acceleration processes in self-field and applied magnetic field thrusters. Proceedings of the 23rd International Electric Propulsion Conference, Seattle WA USA; 1993, IEPC-93-076.

[58] Tikhonov V, Semenikhin S, Polk J. Self-magnetic field impact on MPD thruster's performance with external magnetic field. Proceedings of the 26th International Electric Propulsion Conference, Kitakyushu Japan; 1999, IEPC-99-176. 
[59] Semenikhin S, Tikhonov V. The influence of cathode design on the performance and characteristics of MPD thrusters with applied magnetic field. In: Proceedings of the 3rd Russian-German Conference on Electric Propulsion Engines and their Technical Applications, Stuttgart Germany; 1994, p. M27-M31.

[60] Popov A, Tikhonov V. Theoretical and experimental research on magnetoplasmadyanamic thrusters. Proceedings of the Russian Conference on Electric Propulsion, No. RGC-EP-92-16, MAI, Moscow; 1992.

[61] Tikhonov V, Semenikihin S, Brophy JR, Polk JE. The experimental performance of the $100 \mathrm{~kW}$ lithium MPD thruster with external magnetic field. Proceedings of the 24th International Electric Propulsion Conference, Moscow Russia; 1995, IEPC-95105.

[62] Popov G, Kim V, Tikhonov V, Semenikhin S, Tibrina M. High-power lithium-fed MPDT research. Fourth (Final) quarterly report on contract 960938 between RIAME and JPL. RIAME MAI, Moscow; 1998.

[63] Polk J. Mechanisms of cathode erosion in high power plasma thrusters. $\mathrm{PhD}$ thesis, Princeton University, Princeton NJ USA; 1996.

[64] St. Rock B, Blandino J, Anderson K, Polk J. Thermal analysis of a lithium vaporizer for a high-power magnetoplasmadynamic thruster. J Propulsion and Power 2006; 22:1098-1110.

[65] St. Rock B, Blandino J. Thermal-fluid analysis of a lithium vaporizer for a highpower Lorentz force accelerator. Proceedings of the 42nd /ASME/SAE/ASEE Joint Propulsion Conference and Exhibit, Sacramento CA USA; 2006, AIAA-2006-5021. 
[66] Polzin K, Markusic T, Stanojev B, Marrese-Reading C. Integrated liquid bismuth propellant feed system. Proceedings of the 42nd ASME/SAE/ASEE Joint Propulsion Conference and Exhibit, Sacramento CA USA; 2006, AIAA-2006-4636.

[67] Boyd I, Scavezze K, Cai C, Polk J, Choueiri, E. Analysis of plume backflow from a lithium magnetoplasmadynamic thruster. Proceedings of the 29th International Electric Propulsion Conference, Princeton University, Princeton NJ USA; 2005, IEPC-2005-014.

[68] Dailey CL, Lovberg RH. The PIT Mk V pulsed inductive thruster. NASA-CR$191155 ; 1993$.

[69] Russell D, Poylio J, Goldstein W, Lovberg R, Dailey C, Jackson B. The PIT Mark VI pulsed inductive thruster. Proceedings of the Space 2004 Conference and Exhibit, San Diego CA USA; 2004, AIAA-2004-6054.

[70] Poylio J, Russell D, Goldstein W, Lovberg R, Dailey C, and Jackson B. Pulsed inductive thruster: flight-scale proof of concept demonstrator. Proceedings of the 40th AIAA/ASME/SAE/ASEE Joint Propulsion Conference and Exhibit, Fort Lauderdale FL USA; 20004, AIAA 2004-3640.

[71] Russell D, Franco W, Lesky O, Timko M, Lovberg R. The nuclear-electric pulsed inductive thruster (NuPIT). NASA contractor report DRD-1052MA-002; 2005.

[72] Frisbee RH, Mikellides IG. The nuclear-electric pulsed inductive thruster (NuPIT): mission analysis for Prometheus. Proceedings of the 41st AIAA/ASME/SAE/ASEE Joint Propulsion Conference and Exhibit, Tucson AZ USA; 2005, AIAA-20053892. 
[73] Mikellides P. MACH2 simulations of the pulsed inductive thruster. Proceedings of the 38th AIAA/ASME/SAE/ASEE Joint Propulsion Conference and Exhibit, Indianapolis IN USA; 2002, AIAA-2002-3807.

[74] Allison D, Mikellides P. A high-temperature, thermal non-equilibrium equation of state for ammonia. International Journal of Thermophysics 2006; 27:794-819.

[75] Frisbee RH, Moeller RC. Identification of mission sensitivities for high-power electric propulsion systems. Proceedings of the 41st AIAA/ASME/SAE/ASEE Joint Propulsion Conference and Exhibit, Tucson AZ USA; 2005, AIAA-2005-3894.

[76] Angelo JA Jr, Buden D. Space nuclear power. Malabar FL: Orbit Book Company, 1985.

[77] Ponamarev-Stepnoi NN. Russian space nuclear power and nuclear thermal propulsion systems. Nuclear News 2000; 43:33-46.

[78] Poston DI, Marcille TF. Design options to reduce development cost of first generation surface reactors. In: El-Genk M, editor. AIP Conference Proceedings 813, Space Technology and Applications International Forum - STAIF 2006, Melville NY: American Institute of Physics, 2006.

[79] Ashcroft J. Invited presentation, Space Technology and Applications International Forum-STAIF 2006, Albuquerque NM USA; 2006.

[80] Noble RJ. Radioisotope electric propulsion of small payloads for regular access to deep space. Proceedings of the $29^{\text {th }}$ AIAA/ASME/SAE/ASEE Joint Propulsion Conference and Exhibit, Monterey CA USA; 1993, AIAA-93-1897.

[81] McNutt R, Gold R, Prockter L, Ostdiek P, Leary J, Fiehler D, Oleson S, Witzberger K. Radioisotope electric propulsion: enabling the decadal survey science goals for 
primitive bodies. In: El-Genk M, editor. AIP Conference Proceedings 813, Space Technology and Applications International Forum - STAIF 2006, Melville NY: American Institute of Physics, 2006.

[82] Oleson S, Benson S, Patterson M, Schreiber J, Fiehler D. Radioisotope electric propulsion missions for New Frontiers class missions. Proceedings of the $28^{\text {th }}$ International Electric Propulsion Conference, Toulouse France; 2003, IEPC-20030137.

[83] Fiehler D, Oleson S. Mission steering profiles of outer planetary orbiters using radioisotope electric propulsion. NASA TM-2004-212877; 2004.

[84] Kristalinski A, Fisher J, Cassady RJ, Chapman J. Radioisotope powered missions to Martian moons using electric propulsion. In: El-Genk M, editor. AIP Conference Proceedings 699, Space Technology and Applications International Forum - STAIF 2004, Melville NY: American Institute of Physics, 2004.

[85] Schmidt G. Radioisotope power systems (RPS) for New Frontiers applications. In" El-Genk M, editor. AIP Conference Proceedings 699, Space Technology and Applications International Forum - STAIF 2004, Melville NY: American Institute of Physics, 2004.

[86] Thieme L, Schreiber J. NASA GRC Stirling technology development overview. In: El-Genk M, editor. AIP Conference Proceedings 654, Space Technology and Applications International Forum - STAIF 2003, Melville NY: American Institute of Physics, 2003. 
[87] Wood JG. Status of free-piston Stirling technology at Sunpower. Proceedings of the 1st International Energy Conversion Engineering Conference, Portsmouth VA USA; 2003, AIAA-2003-6056.

[88] Hamley J, Sankovic J, Miller J, Lynn P, O’Neill M, Oleson S. Hall thruster direct drive demonstration. Proceedings of the $33^{\text {rd }}$ AIAA/ASME/SAE/ASEE Joint Propulsion Conference and Exhibit, Seattle WA USA; 1997, AIAA-97-2787.

[89] Hoskins WA, Homiak D, Cassady RJ, Kerslake T, Peterson T, Ferguson D. Direct drive hall thruster system development. Proceedings of the $39^{\text {th }}$ AIAA/ASME/ SAE/ASEE Joint Propulsion Conference and Exhibit, Huntsville AL USA; 2003; AIAA-2003-4726.

[90] Space Studies Board. New frontiers in the solar system: an integrated exploration strategy. NRC planetary decadal report. Washington DC USA; 2002.

[91] Oleson S, Benson S, Gefert L, Patterson M, Schreiber J. Radioisotope electric propulsion for fast outer planetary orbiters. Proceedings of the $38^{\text {th }}$ AIAA/ASME/SAE/ASEE Joint Propulsion Conference and Exhibit, Indianapolis IN USA; 2002, AIAA-2002-3967.

[92] Pantano D, Dottore F, Tobery W, Geng S, Schreiber J, Palko J. Utilizing radioisotope power system waste heat for spacecraft thermal management. Proceedings of the $3^{\text {rd }}$ International Energy Conversion Engineering Conference, San Francisco CA USA; 2005, AIAA-2005-5548. 


\section{Figure Captions:}

Fig 1 Electrostatic thrusters: (a) gridded ion thruster; (b) Hall-effect thruster

Fig 2 Electromagnetic thrusters: (a) MPD thruster; (b) Pulsed Inductive Thruster

Fig 3 Plasma wave thruster concepts: (a) ECR thruster; (b) VASIMR thruster

Fig 4 Schematic of NEP key system components

Fig 5 (a) GRC HIPEP ion thruster; (b) JPL NEXIS ion thruster

Fig 6 VHITAL-160 thruster (a) mounted to tank flange, and (b) operating at 25-kWe at the TsNIIMASH test facility

Fig 7 Schematic of $\mathrm{ALFA}^{2}$ thruster (a) cutaway side view; (b) front view showing magnet coils and thruster

Fig 8 TRW Pulsed Inductive Thruster (a) front view showing drive coil; (b) back view showing capacitors and power train

Fig 9 Comparison of relative IMLEO (top) and trip times (bottom)

Fig 10 Comparison of thruster relative parts count

Fig 11 Size comparison for a $1-\mathrm{MW}_{\mathrm{e}}$ total bus power system

Fig 12 Comparison of approaches to provide REP system power

Fig 13 Representative outer planet mission times using REP

\section{Table captions:}

Table 1 JMO electric propulsion systems challenges 


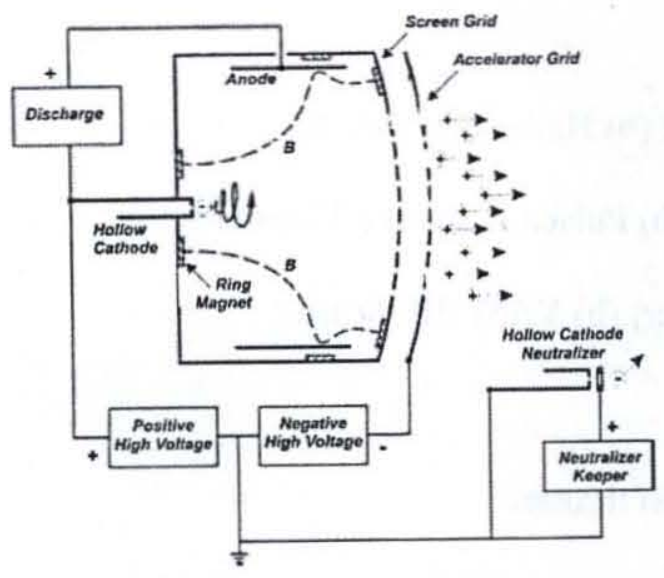

(a)

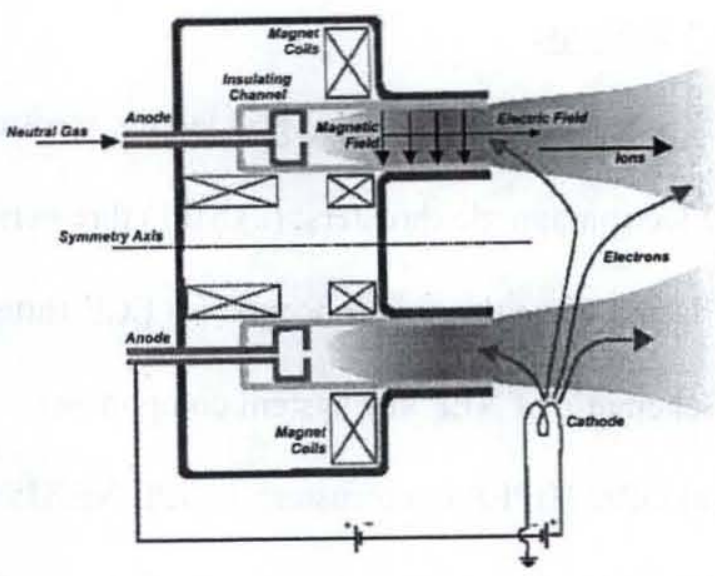

(b)

Fig. 1. Electrostatic thrusters: (a) gridded ion thruster; (b) Hall-effect thruster 


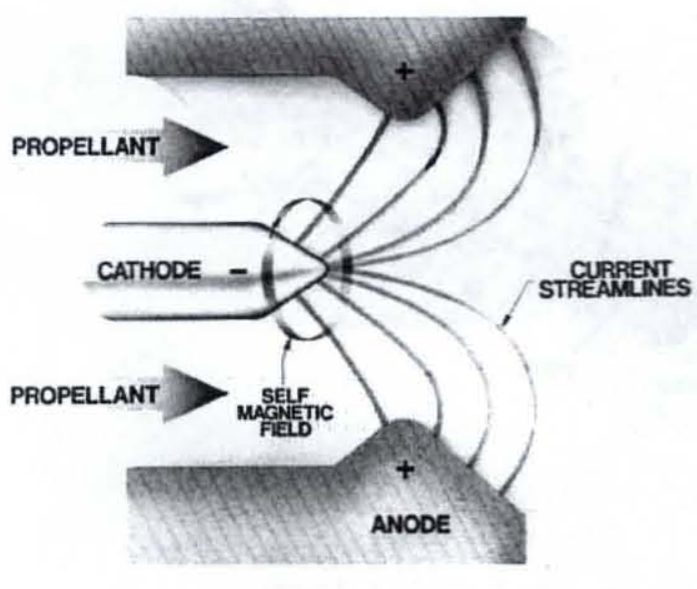

(a)

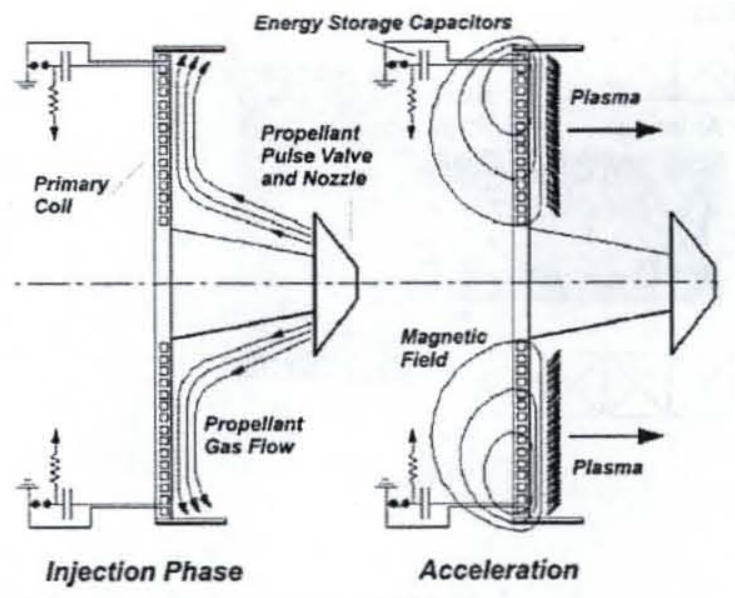

(b)

Fig. 2. Electromagnetic thrusters: (a) MPD thruster; (b) Pulsed Inductive Thruster 


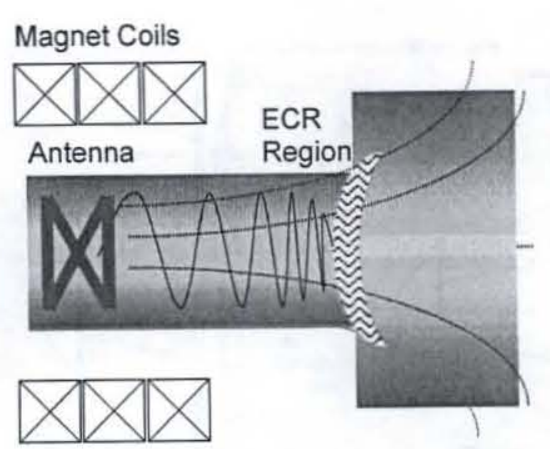

(a)

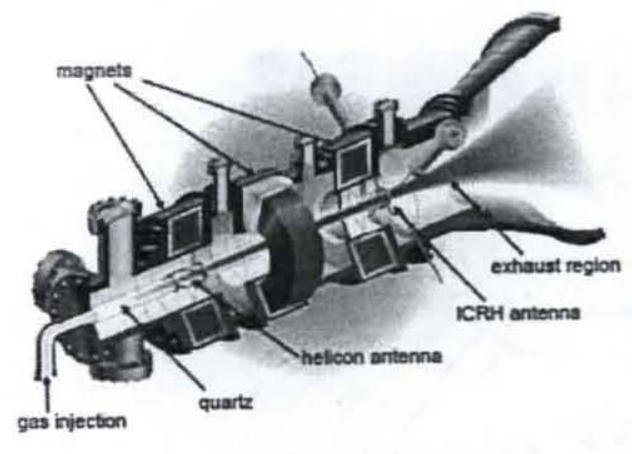

(b)

Fig. 3. Plasma wave thruster concepts: (a) ECR thruster; (b) VASIMR thruster 


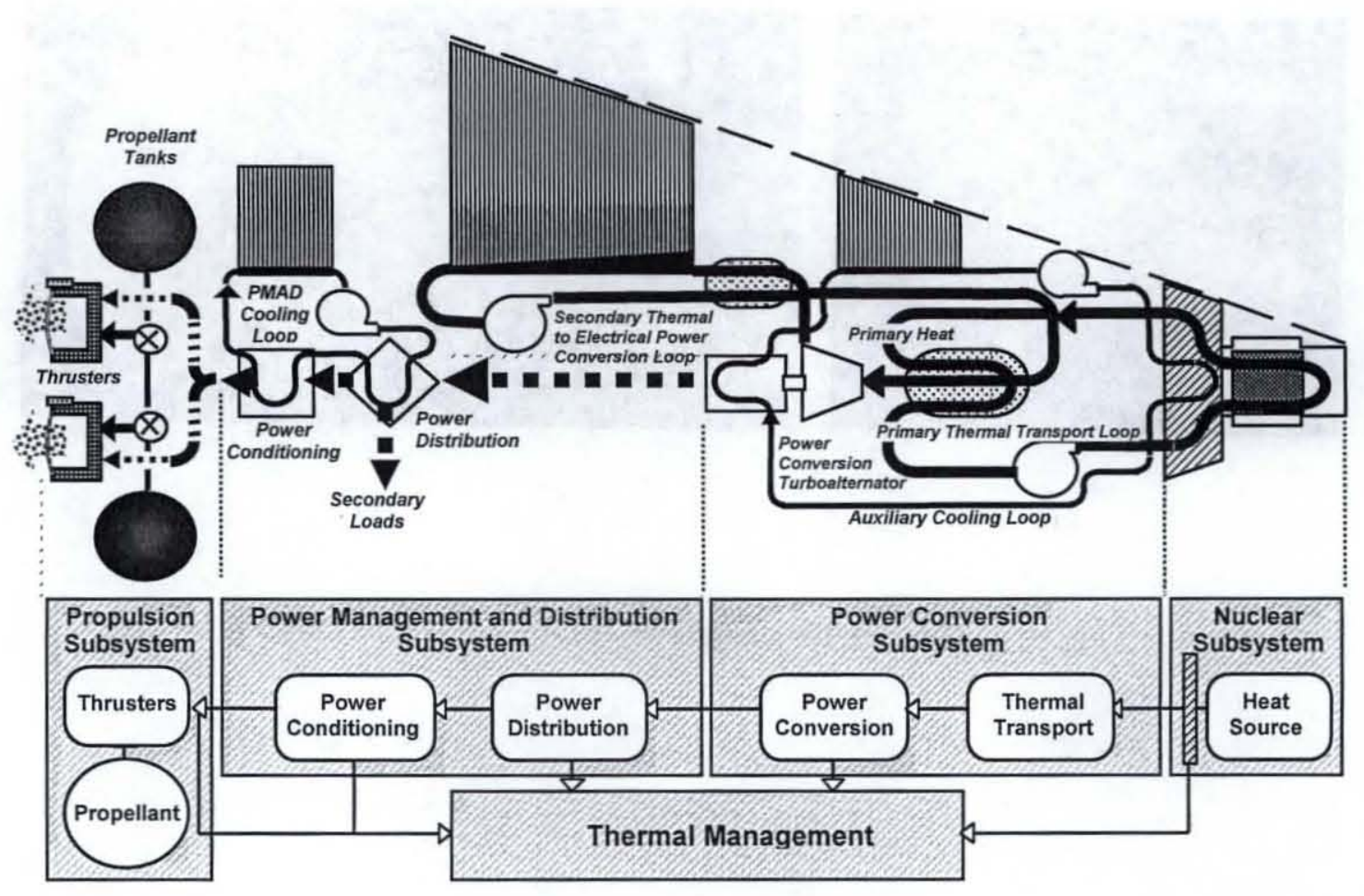

Fig. 4. Schematic of NEP key system components 


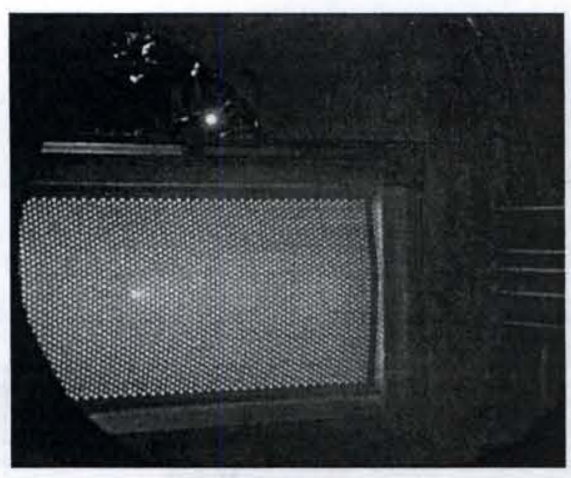

(a)

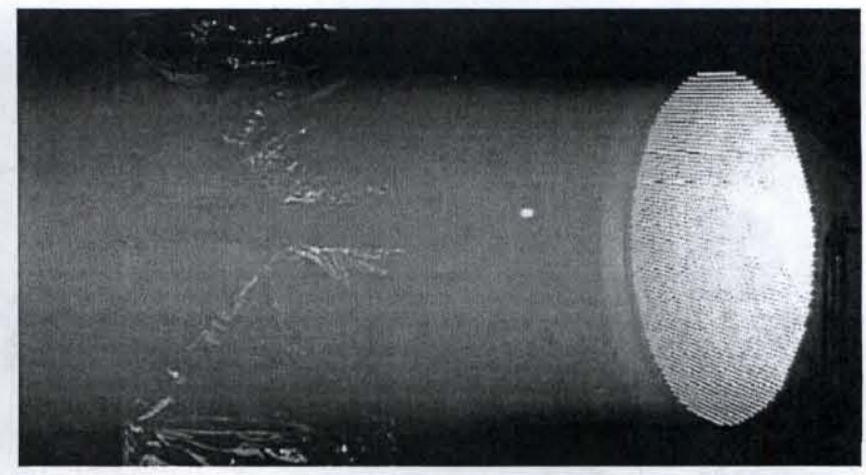

(b)

Fig. 5. (a) GRC HIPEP ion thruster; (b) JPL NEXIS ion thruster 


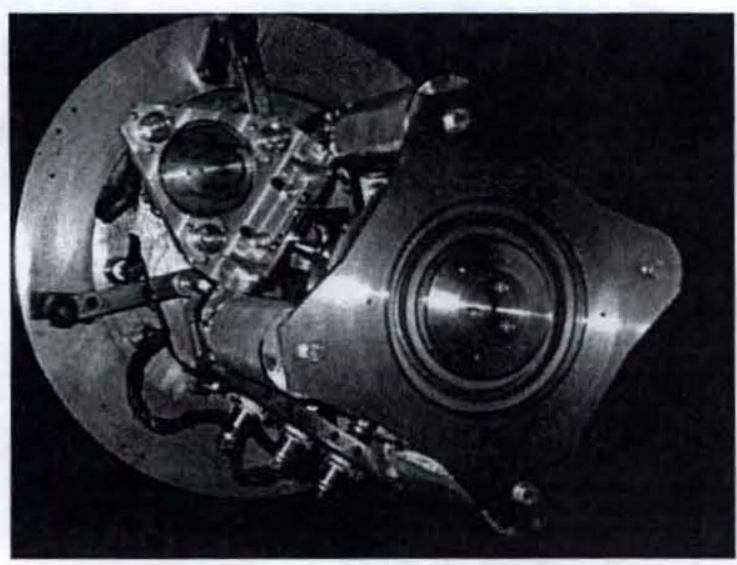

(a)

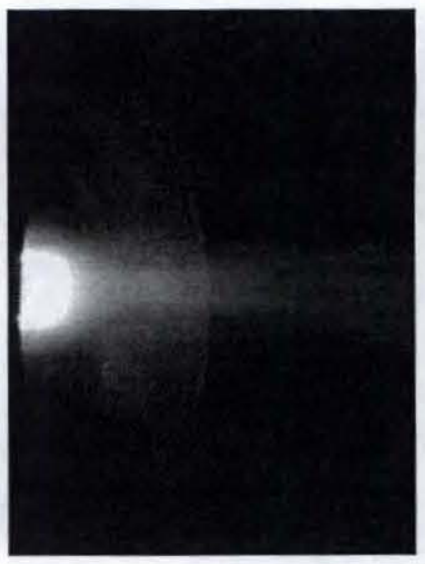

(b)

Fig. 6. VHITAL-160 thruster (a) mounted to tank flange, and (b) operating at 25-kWe at the TsNIIMASH test facility 


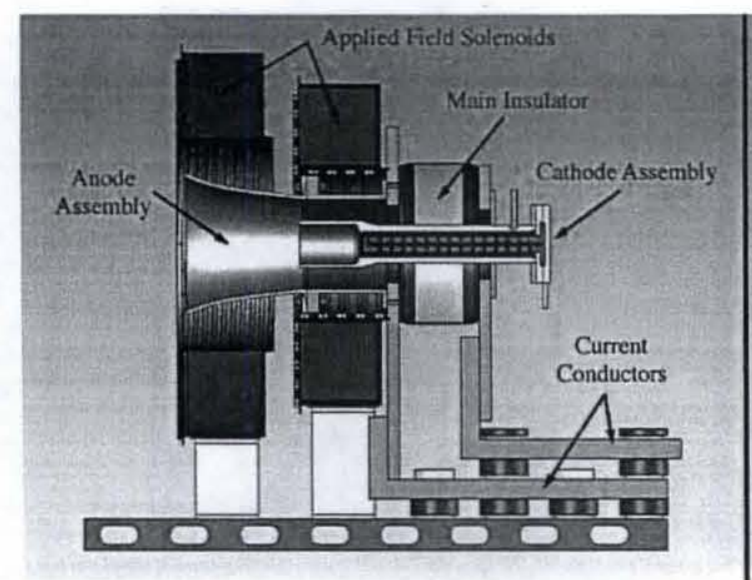

(a)

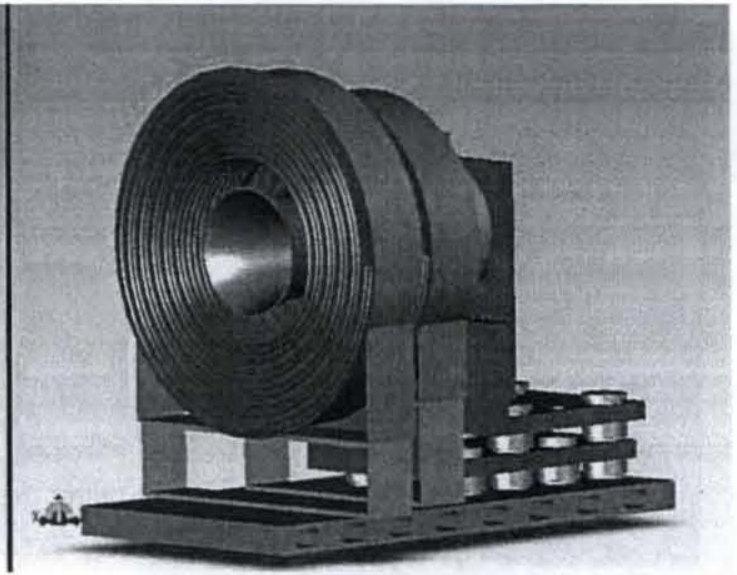

(b)

Fig. 7. Schematic of ALFA ${ }^{2}$ thruster (a) cutaway side view; (b) front view showing magnet coils and thruster 


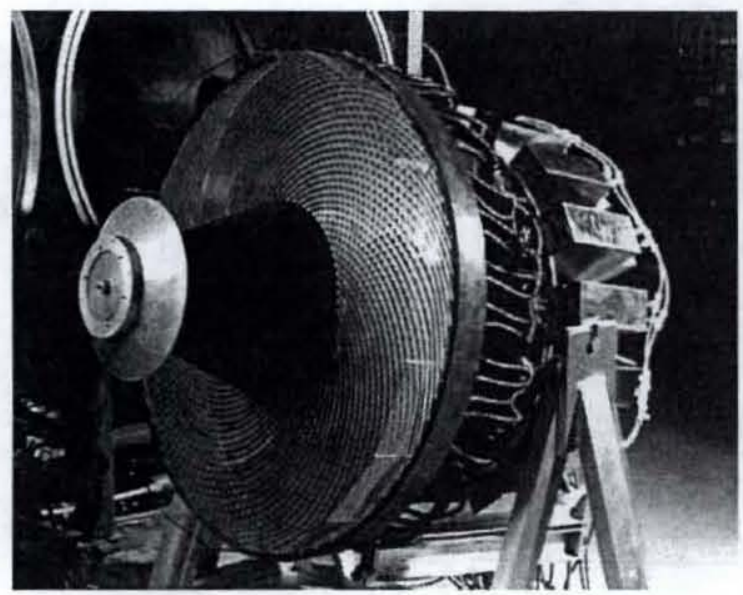

(a)

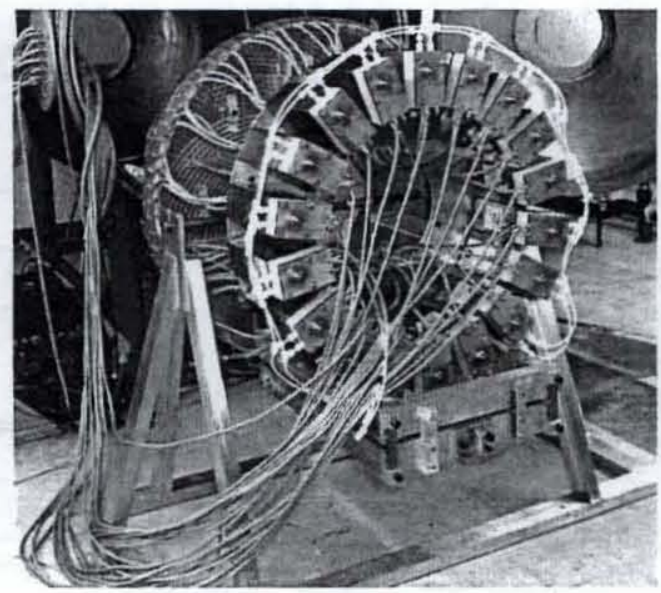

(b)

Fig. 8. TRW Pulsed Inductive Thruster (a) front view showing drive coil; (b) back view showing capacitors and power train 

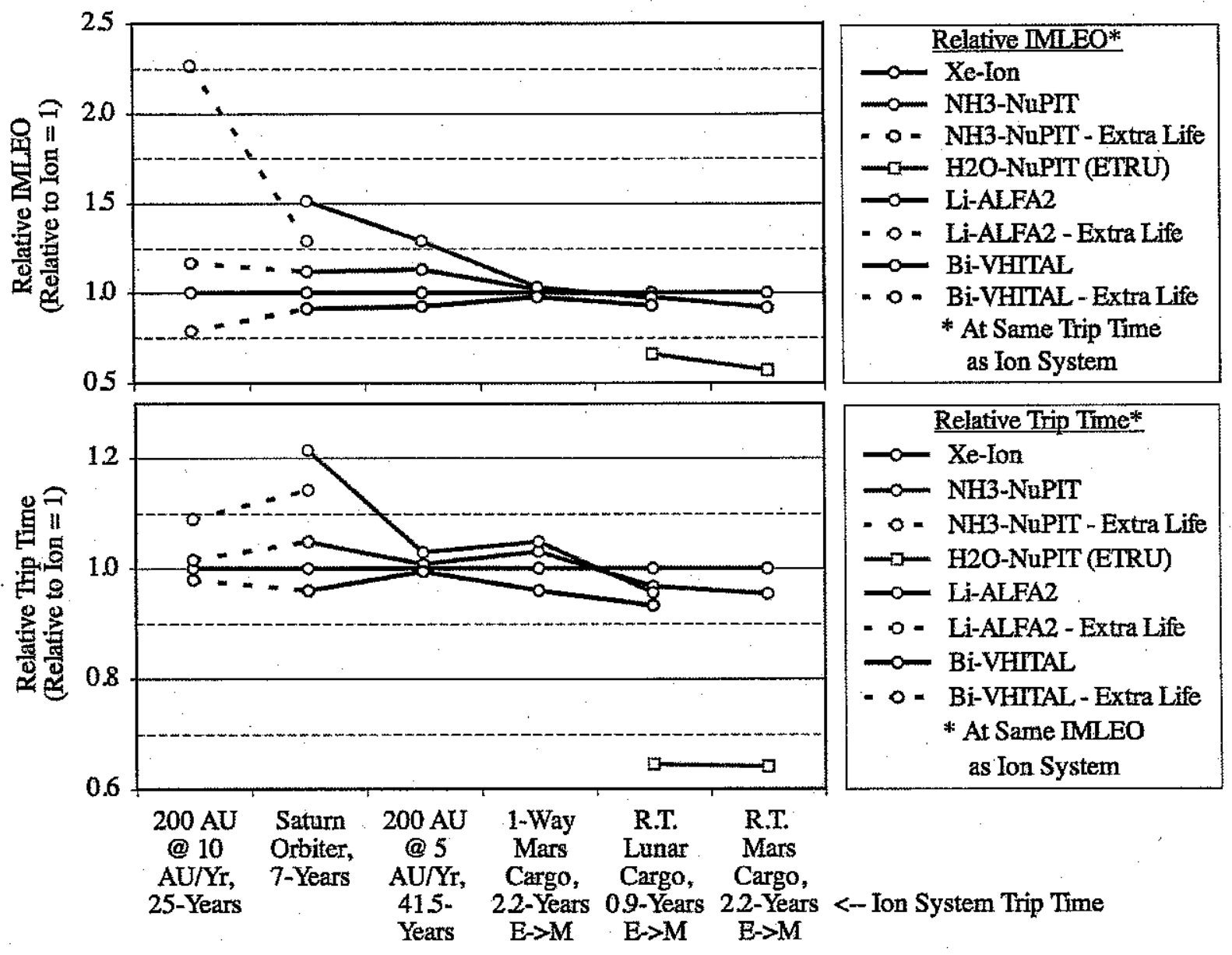

Fig. 9. Comparison of relative IMLEO (top) and trip times (bottom) 


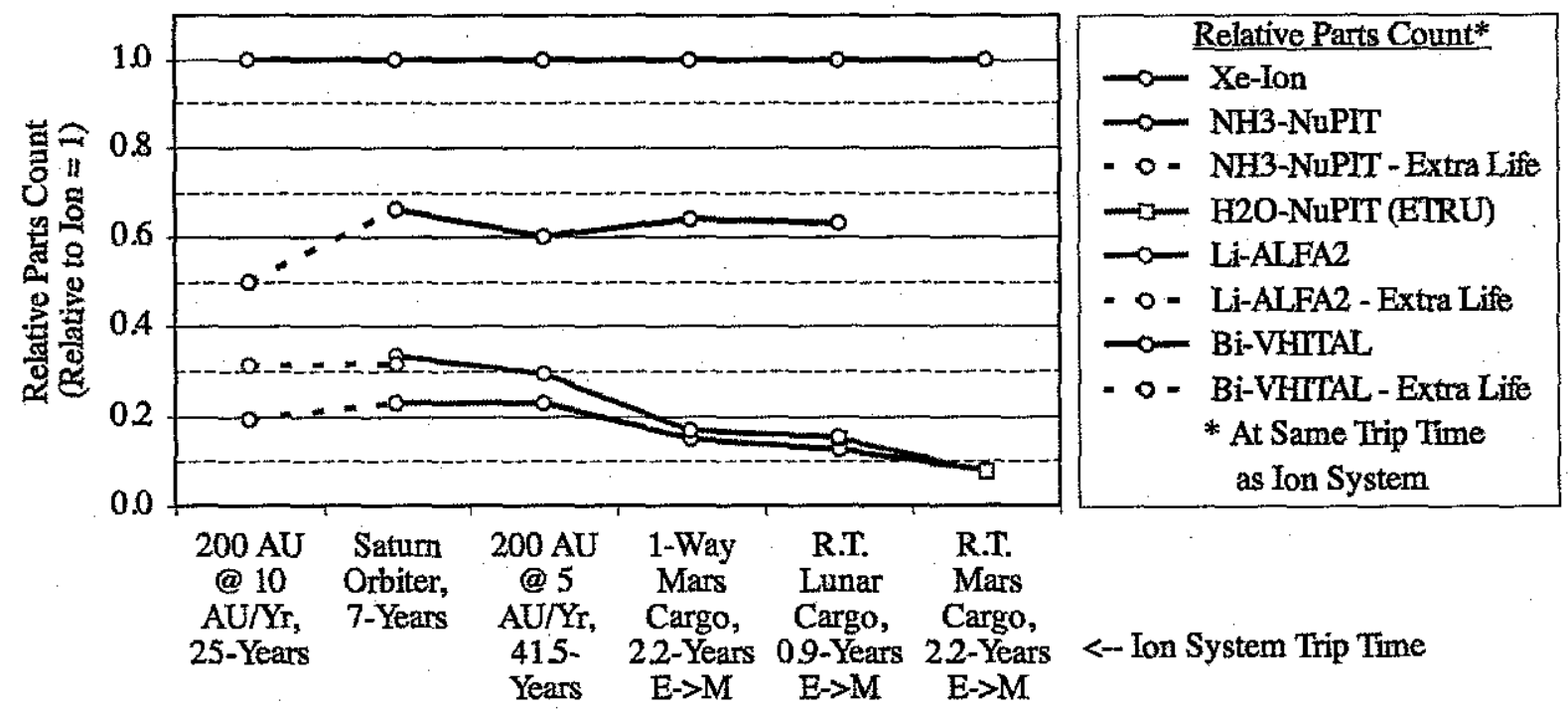

Fig. 10. Comparison of thruster relative parts count 


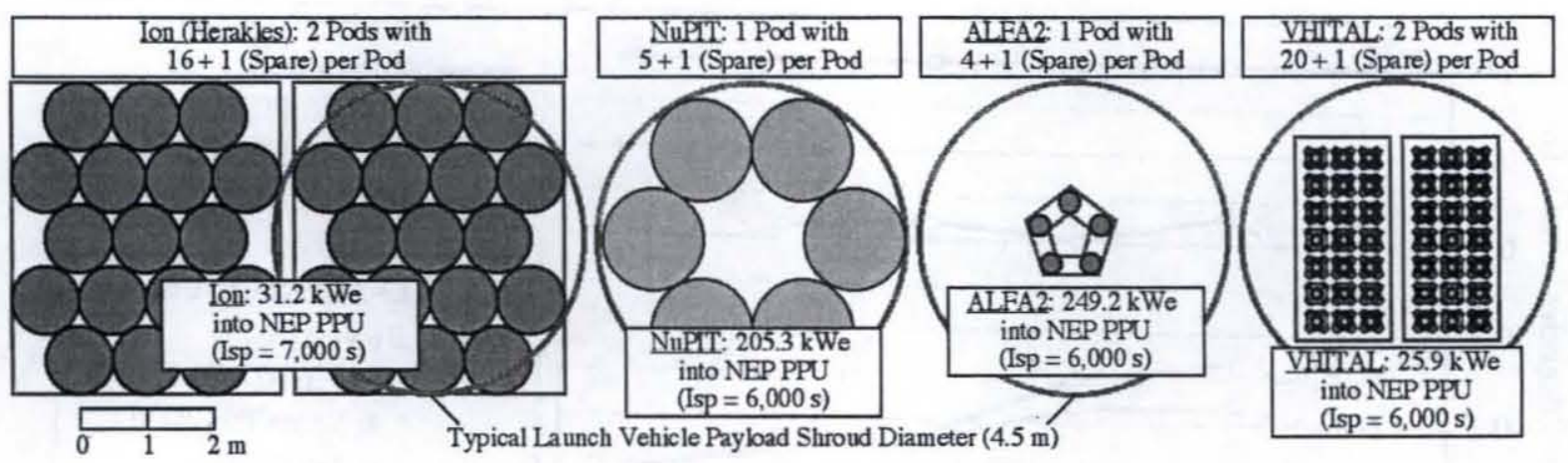

Fig. 11. Size comparison for a $1-\mathrm{MW}_{\mathrm{e}}$ total bus power system 


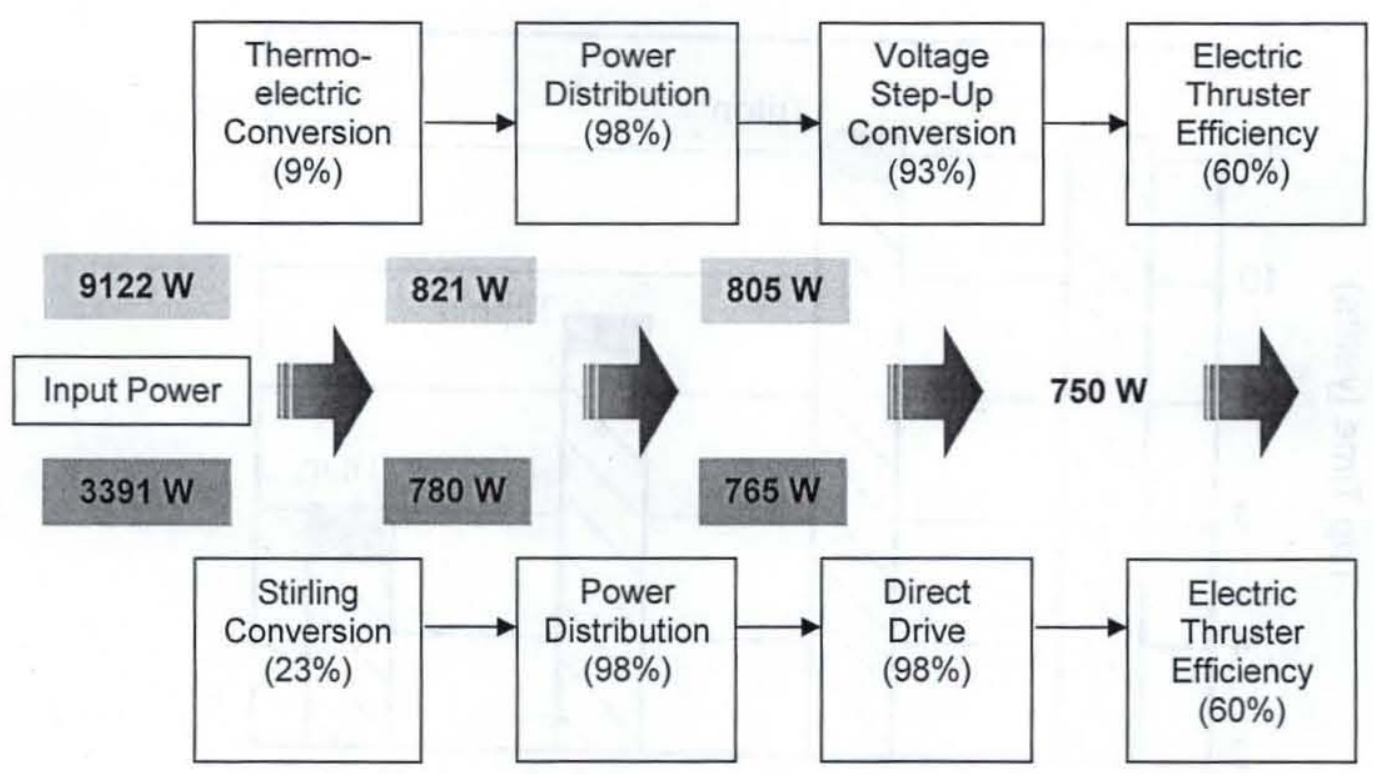

Fig. 12. Comparison of approaches to provide REP system power 


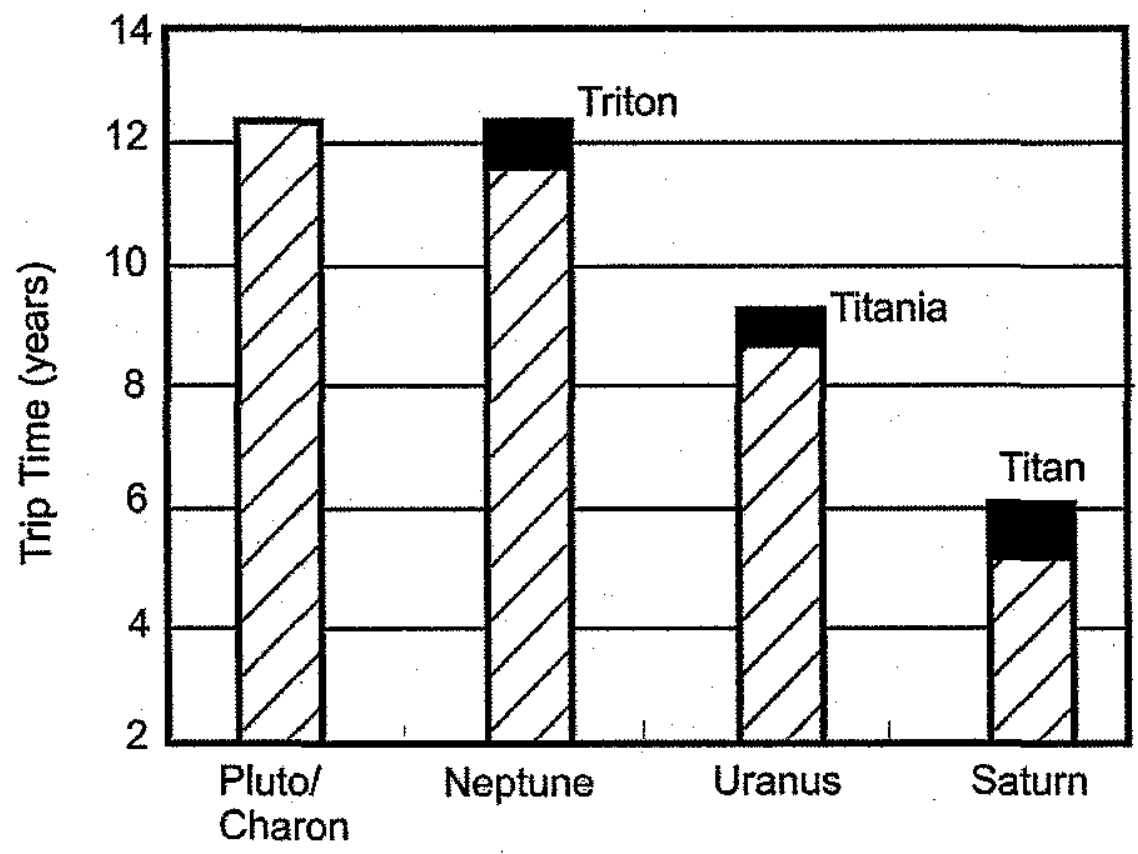

- Spiral Time to Target's Moon

$\square$ Interplanetary Transit Time

Fig. 13. Representative outer planet mission times using REP 


\begin{tabular}{|c|c|c|c|c|c|}
\hline 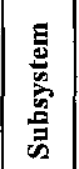 & PARAMETER & $\begin{array}{l}\text { NSTAR } \\
\text { (SOA) }\end{array}$ & ЛМо & $\begin{array}{l}\text { FACTOR OF } \\
\text { IMPROVEMENT } \\
\text { VS SOA }\end{array}$ & DEVELOPMENT APPROACHES \\
\hline \multirow{7}{*}{ 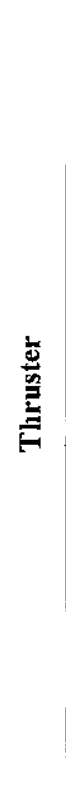 } & Power $(\mathrm{kW})$ & 2.3 & $\begin{array}{l}20 \text { to } \\
50\end{array}$ & 9 to $22 \mathrm{X}$ & $\begin{array}{l}\text { Increase size and beam area of thruster either with } \\
\text { larger circular or rectangular discharge chamber }\end{array}$ \\
\hline & $\begin{array}{l}\text { Specific } \\
\text { Impulse (s) }\end{array}$ & 3170 & $\begin{array}{l}6000 \\
\text { to } \\
9000\end{array}$ & 2 to $3 \mathrm{X}$ & Raise ion beam voltage \\
\hline & $\begin{array}{l}\text { İon Beam } \\
\text { Voltage (V) }\end{array}$ & 1100 & $\begin{array}{l}\text { Up to } \\
7000\end{array}$ & $>6 \mathrm{X}$ & $\begin{array}{l}\text { Increase voltages to thruster, increase/improve } \\
\text { isolator/insulator designs by increasing size and } \\
\text { gap }\end{array}$ \\
\hline & $\begin{array}{l}\text { Ion Beam } \\
\text { Current }(A)\end{array}$ & 1.3 & $>8$ & $>6 \mathrm{X}$ & $\begin{array}{l}\text { Develop larger electron sources, either hollow } \\
\text { cathode or microwave }\end{array}$ \\
\hline & $\begin{array}{l}\text { Xenon } \\
\text { Throughput } \\
\text { (kg) }\end{array}$ & 229 & $>2000$ & $>8.7 \mathrm{X}$ & $\begin{array}{l}\text { Utilize erosion resistant grid materials made from } \\
\text { carbon. Test and model for grid wear to predict } \\
\text { life compliance }\end{array}$ \\
\hline & $\begin{array}{l}\text { Life at } \\
\text { Full power }(y r)\end{array}$ & 1.3 & $\begin{array}{l}6 \text { to } \\
10\end{array}$ & 5 to $8 \mathrm{X}$ & $\begin{array}{l}\text { Develop long life hollow cathode or microwave } \\
\text { sources. Use advanced isolator/insulator materials } \\
\text { and designs to avoid long-time operation failure. } \\
\text { Test and model failure mechanisms to predict life } \\
\text { compliance }\end{array}$ \\
\hline & $\begin{array}{l}\text { Specific Mass } \\
(\mathrm{kg} / \mathrm{kW})\end{array}$ & 3.6 & $<2$ & $>1.8 \mathrm{X}$ less & $\begin{array}{l}\text { Develop larger thrusters that can provide full } \\
\text { design life capability with one set }\end{array}$ \\
\hline \multirow{5}{*}{ Q } & Input Voltage & $\begin{array}{l}80-160 \\
\text { VDC }\end{array}$ & $\begin{array}{l}100 \text { to } \\
600 \\
\text { VDC } \\
\text { or } \\
\text { VAC } \\
\end{array}$ & 1 to $4 \mathrm{XSOA}$ & $\begin{array}{l}\text { Utilize larger stepping transformers, either solid } \\
\text { state (DC) or transformer pre-stage (AC) }\end{array}$ \\
\hline & $\begin{array}{l}\text { Output } \\
\text { Power (kW) }\end{array}$ & 2.3 & $\begin{array}{l}20 \text { to } \\
50\end{array}$ & 9 to $22 \mathrm{X}$ & Build higher power modules \\
\hline & \begin{tabular}{|l} 
Beam \\
Voltage (V)
\end{tabular} & 1100 & $\begin{array}{l}\text { Up to } \\
7000\end{array}$ & $>6 \mathrm{X}$ & Improve module voltage stepping technology $6 \mathrm{X}$ \\
\hline & $\begin{array}{l}\text { Radiation } \\
\text { Qualification } \\
\text { Level (kRad) } \\
\end{array}$ & 100 & $>5000$ & $50 \mathrm{X}$ & $\begin{array}{l}\text { Develop higher radiation hardened parts and } \\
\text { shielding }\end{array}$ \\
\hline & $\begin{array}{l}\text { Specific mass } \\
(\mathrm{kg} / \mathrm{kW})\end{array}$ & 6 & $<4$ & $1.5 \mathrm{X}$ less & Develop larger beam modules \\
\hline \multirow{2}{*}{ 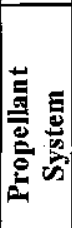 } & $\begin{array}{l}\text { Radiation } \\
\text { Qualification } \\
\text { Level (kRad) } \\
\end{array}$ & 100 & $>5000$ & $50 \times$ & Develop higher radiation hardened components \\
\hline & $\begin{array}{l}\text { Propellant } \\
\text { Loading }(\mathrm{kg})\end{array}$ & 80 & $>8000$ & $100 \mathrm{X}$ & $\begin{array}{l}\text { Develop larger supercritical storage tanks or } \\
\text { develop cryogenic storage systems }\end{array}$ \\
\hline
\end{tabular}

Table 1 JIMO electric propulsion systems challenges 